\title{
Norrisanima miocaena, a new generic name and redescription of a stem balaenopteroid mysticete (Mammalia, Cetacea) from the Miocene of California
}

\author{
Matthew S Leslie ${ }^{\text {Corresp., } 1}$, Carlos M. Peredo ${ }^{2}$, Nicholas D Pyenson ${ }^{3,4}$ \\ 1 Biology Department, Swarthmore College, Swarthmore, PA, United States \\ 2 Department of Earth and Environmental Science, University of Michigan - Ann Arbor, Ann Arbor, Michigan, United States \\ 3 Department of Paleobiology and Vertebrate Zoology, National Museum of Natural History, Smithsonian Institution, Washington, DC, United States \\ 4 Department of Paleotology and Geology, Burke Museum of Natural History and Culture, Seattle, Washington, United States \\ Corresponding Author: Matthew S Leslie \\ Email address: mleslie2@swarthmore.edu
}

Rorqual whales are among the most species rich group of baleen whales (or mysticetes) alive today, yet the monophyly of the traditional grouping (i.e., Balaenopteridae) remains unclear. Additionally, many fossil mysticetes putatively assigned to either Balaenopteridae or Balaenopteroidea may actually belong to stem lineages, although many of these fossil taxa suffer from inadequate descriptions of fragmentary skeletal material. Here we provide a redescription of the holotype of Megaptera miocaena, a fossil balaenopteroid from the Monterey Formation of California, which consists of a partial cranium, a fragment of the rostrum, a single vertebra, and both tympanoperiotics. Kellogg (1922) assigned the type specimen to the genus Megaptera, on the basis of its broad similarities to distinctive traits in the cranium of extant humpback whales (Megaptera novaeangliae (Borowski, 1781)). Subsequent phylogenetic analyses have found these two species as sister taxa in morphological datasets alone; the most recent systematic analyses using both molecular and morphological data sets place Megaptera miocaena as a stem balaenopteroid unrelated to humpback whales. Here, we redescribe the type specimen of Megaptera miocaena in the context of other fossil balaenopteroids discovered in the century since Kellogg's original description and provide a morphological basis for discriminating it from Megaptera novaeangliae. We also provide a new generic name and recombine the taxon as Norrisanima miocaena, gen. nov., to reflect its phylogenetic position outside of crown Balaenopteroidea, unrelated to extant Megaptera. Lastly, we refine the stratigraphic age of Norrisanima miocaena, based on associated microfossils to a Tortonian age (7.6-7.3 Ma), which carries implications for understanding the origin of key features associated with feeding and body size evolution in this group of whales. 


\section{Norrisanima miocaena, a new generic name and redescription of}

\section{2 a stem balaenopteroid mysticete (Mammalia, Cetacea) from the}

\section{Miocene of California}

5 Matthew S. Leslie ${ }^{*}$, Carlos Mauricio Peredo ${ }^{2}$, and Nicholas D. Pyenson ${ }^{3,4}$

2. Department of Earth and Environmental Science, University of Michigan - Ann Arbor, Ann 11 Arbor, MI 48109, USA

3. Department of Paleobiology and Vertebrate Zoology, National Museum of Natural History, Smithsonian Institution, Washington, DC 20560, USA

4. Department of Paleontology and Geology, Burke Museum of Natural History and Culture, 1413 NE 45th Street, Seattle, WA 98105, USA

*Corresponding Author:

Matthew S. Leslie

Swarthmore College

500 College Ave., Swarthmore, PA 19081, USA

Email Address: mleslie2@swarthmore.edu 


\section{ABSTRACT}

28 Rorqual whales are among the most species rich group of baleen whales (or mysticetes) alive 29 today, yet the monophyly of the traditional grouping (i.e., Balaenopteridae) remains unclear.

30 Additionally, many fossil mysticetes putatively assigned to either Balaenopteridae or

31 Balaenopteroidea may actually belong to stem lineages, although many of these fossil taxa suffer

32 from inadequate descriptions of fragmentary skeletal material. Here we provide a redescription

33 of the holotype of Megaptera miocaena, a fossil balaenopteroid from the Monterey Formation of

34 California, which consists of a partial cranium, a fragment of the rostrum, a single vertebra, and

35 both tympanoperiotics. Kellogg (1922) assigned the type specimen to the genus Megaptera, on

36 the basis of its broad similarities to distinctive traits in the cranium of extant humpback whales

37 (Megaptera novaeangliae (Borowski, 1781)). Subsequent phylogenetic analyses have found

38 these two species as sister taxa in morphological datasets alone; the most recent systematic

39 analyses using both molecular and morphological data sets place Megaptera miocaena as a stem

40 balaenopteroid unrelated to humpback whales. Here, we redescribe the type specimen of

41 Megaptera miocaena in the context of other fossil balaenopteroids discovered in the century

42 since Kellogg's original description and provide a morphological basis for discriminating it from

43 Megaptera novaeangliae. We also provide a new generic name and recombine the taxon as

44 Norrisanima miocaena, gen. nov., to reflect its phylogenetic position outside of crown

45 Balaenopteroidea, unrelated to extant Megaptera. Lastly, we refine the stratigraphic age of

46 Norrisanima miocaena, based on associated microfossils to a Tortonian age (7.6-7.3 Ma), which

47 carries implications for understanding the origin of key features associated with feeding and

48 body size evolution in this group of whales. 
50

51

52

53

54

55

56

57

58

59

60

61

62

63

64

65

66

67

68

69

70

71

72

\section{Introduction}

Rorqual whales include the largest vertebrates to have ever evolved in the history of life. Despite recent insights into evolutionary trends in body size for these taxa (Slater et al. 2017), the overall

phylogenetic relationships among extant lineages of rorquals remain a work in progress (Árnason et al. 2018). Specifically, questions remain regarding the monophyly of Balaenopteridae (relative to Eschrichtius robustus (Lilljeborg 1861)), or living gray whales) and the monophyly of the clade Balaenoptera Lacépède 1804 (with regard to the living genus Megaptera Gray 1846). Three main hypotheses for the relationships among Eschrichtius, Balaenoptera, and Megaptera reoccur predominantly in the recent literature (e.g., Deméré et al. 2008; McGowen et al. 2009; Gatesy et al. 2013; Marx \& Fordyce 2015; Marx \& Kohno 2016; Slater et al. 2017; Árnason et al. 2018). The first is the traditional view of a monophyletic Eschrichtiidae and Balaenopteridae as sister clades with Megaptera sister to Balaenoptera, within Balaenopteridae (Fig. 1A). This view matches classification schemes built in the 20th century (e.g., Rice 1998, and references therein) and the phylogenetic relationships derived from only morphological data sets (e.g., Marx 2011; Bosselaers \& Post 2010; Boessenecker \& Fordyce 2015), with the exception of a single combined morphological and molecular data set (Geisler et al. 2017). The second reoccurring hypothesis (Fig. 1B) includes Eschrichtiidae nested within Balaenopteridae, and Megaptera within Balaenoptera. This overall pattern has been supported by molecular (McGowen et al. 2009; Sasaki et al. 2006) and combined morphological and molecular data sets (Marx \& Fordyce 2015; Slater et al. 2017), including both fossil and extant taxa, as well from putative extinct members of Balaenopteridae and Eschrichtiidae sensu lato (Marx \& Kohno 2016; Slater et al. 2017). By contrast, two molecular studies recovering the same pattern (McGowen et al. 2009; Sasaki et al. 2006) used only extant lineages, highlighting the 
73 inconsistent taxon sampling across these studies. The third hypothesis (Fig. 1C) built from

74 combined morphological and molecular data, or strictly molecular data, places Eschrichtiidae

75 and Balaenopteridae as sister clades with Megaptera nested within Balaenoptera and sister to $B$.

76 physalus Linnaeus, 1758 (Sasaki et al. 2006; Deméré et al. 2008; Gatesy et al. 2013). This

77 hypothesis also recovers a monophyletic Balaenopteridae but does not recover a monophyletic

78 genus Balaenoptera (Fig 1C).

Megaptera miocaena, from the Monterey Formation of California, is a stem

balaenopteroid described nearly a century ago (Kellogg, 1922). Kellogg (1922) originally

81 assigned this species to the genus Megaptera based on the wide breadth of the cranium relative

82 to its length and similarities to the extant M. novaeangliae (Borowski, 1781) in the

83 tympanoperiotics. Two studies have discussed the taxonomic position of Megaptera miocaena in

84 detail. Deméré et al. (2005) noted that M. miocaena lacks any of the autapomorphies of the

85 extant M. novaeangliae and they explicitly opined that it is not a species of Megaptera and,

86 therefore warrants placement in a new genus. Later, Marx and Fordyce (2015), using

87 phylogenetic analyses of morphology and DNA recovered M. miocaena as a stem taxon, outside

88 of the group of formed by living rorquals and gray whales. Several other recent phylogenetic

89 analyses based on morphological and molecular data sets have also failed to recover the putative

90 congeneric sister relationship between M. miocaena and M. novaeangliae (Deméré et al. 2008;

91 Gatesy et al. 2013; McGowen et al. 2009; Marx \& Fordyce 2015; Marx \& Kohno 2016; Slater et

92 al. 2017). Interestingly, the only phylogenetic analyses that have recovered M. miocaena as the

93 sister taxon of extant M. novaeangliae use exclusively morphological data (Marx 2011;

94 Boessenecker \& Fordyce 2015; Boessenecker \& Fordyce 2017). 

basis for discriminating the putative similarities it shares with $M$. novaeangliae, and present the

97 balaenopteroid synapomorphies that it lacks, affirming its status as a stem balaenopteroid. These morphological observations supplement the existing phylogenetic framework, using comprehensive molecular and morphological datasets, which places M. miocaena outside of crown Balaenopteroidea (e.g., Marx \& Fordyce 2015; Slater et al. 2017). Given this placement, we follow Deméré et al. (2005)'s recommendation to assign the specimen described by Kellogg

102 (1922) to a new generic name: Norrisanima, nov. gen. Herein, we provide a detailed

103 redescription of this taxon, explain how it differs from Megaptera and other crown and fossil

104 balaenopteroids, and provide more details about its stratigraphic age and relevance for the 105 evolution of rorquals and gray whales.

\section{Methods}

Anatomical terminology follows Mead \& Fordyce (2009). Permits for collection were not required, as the specimen was collected near Lompoc, California in 1919 and has been

111 accessioned at the Smithsonian Institution ever since. For comparisons with crown

112 balaenopteroids, we examined the following periotics in the collections of the Division of

113 Mammals in the Department of Vertebrate Zoology at the Smithsonian's National Museum of

114 Natural History (all right periotics except where noted): M. novaeangliae (USNM 486175),

115 Balaenoptera borealis Lesson, 1828 (USNM 504699), B. physalus (USNM 237566-left

116 periotic), and Balaenoptera bonaerensis Burmeister, 1867 (USNM 504953). 
119 Institutional Abbreviation

120 USNM, Departments of Paleobiology (holotype) and Vertebrate Zoology (Division of Mammals

121 for comparative specimens), National Museum of Natural History, Smithsonian Institution,

122 Washington, District of Columbia, USA.

123

124 3D surface scanning-cranium

125 We used an Artec Eva (Artec Europe, Luxembourg) hand-held structured light scanner to create

126 a 3D model of the cranium of the holotype specimen (USNM 10300). Because of the size and

127 weight of the holotype specimen $(>200 \mathrm{~kg})$, we scanned the dorsal and ventral sides separately.

128 We scanned at a rate of two frames per second and completed several scans to cover the surface

129 of each side. All data cleaning, processing, and model creation were completed in the Artec

130 Studio12 software package. We imported all scans for the dorsal side into a single project and

131 performed a global registration, then aligned each scan incrementally using a set of three shared

132 landmarks in the Align Tool Function and finished by cleaning and trimming the scan to remove

133 data collected from the specimen housing jacket. The process was then repeated for the ventral

134 side. Thus, scans from each side were aligned and trimmed in isolation from the other to create a

135 composite model for each side. Then, we conducted a final global registration on the two models

136 and again used the Align Tool to join the two halves into a single, final 3D model. We then

137 completed another global registration and created a complete 3D model using the Fast Fusion

138 tool; this model was not watertight. Holes in the model up to and including 150 pixels were filled

139 using the Hole Fill tool; all other holes were left open. Most of the holes occurred in deep

140 recesses where the scanner could not collect data, or where the storage jacket obscured both the 
141 dorsal and ventral sides of the cranium. Once the model was complete, we exported it as STL

142 format for the distributed model (available in Supplemental Material), and for import into

143 MeshLab (Cignoni et al. 2008) where we exported PNG image files.

145 CT scanning-tympanoperiotics

146 We scanned two periotics and one bulla from the holotype at the Smithsonian Institution Bio-

147 Imaging Research Center in the Department of Anthropology at the National Museum of Natural

148 History in Washington, D.C., U.S.A. Computed tomography (CT) data were collected with a

149 Siemens Somatom Emotion 6 (Siemens Medical Solutions, Erlangen, Germany) at slice

150 thickness of $0.63 \mathrm{~mm}$, resulting in a $3 \mathrm{D}$ reconstruction increment of $0.30 \mathrm{~mm}$. DICOM files were

151 processed by importing image files in Mimics Innovation Suite 19 (Materialise NV, Leuven,

152 Belgium). In Mimics, we created a mask based on the threshold of bone relative to the nominal

153 density of air. A 3D object was then created from this mask, and exported as a binary STL file.

154 The STL file was then opened in MeshLab (Cignoni et al. 2008) for final editing to create 3D

155 models and figures of the external morphology. The original DICOM files, STL files, and the 3D

156 files of the cranium, are archived at Zenodo (http://zenodo.org) at the following DOI:

$15710.5281 /$ zenodo.3245500. 3D models of the tympanoperotics and surface scan models of the

158 cranium will be available for viewing and download on the Smithsonian X 3D website

159 (http://3d.si.edu).

160

\section{Phylogenetic nomenclature}

162 We followed the recommendations of Joyce et al. (2004) for the conversion of select ranked

163 taxonomic cetacean names to phylogenetically defined ones in this study, following similar steps 
164 by Pyenson et al. (2015). For these purposes, we used abbreviations NCN for New Clade Name

165 and CCN for Converted Clade Name. Below, we clarify our precise definitions for these clades

166 (see PhyloCode, 2014, Article 9.3; Cantino \& de Queiroz, 2014), and we also provide full

167 citations for the names of specifier species, when warranted.

168

169 Nomenclatural acts

170 The electronic version of this article adheres to the amended International Code of Zoological

171 Nomenclature (ICZN). Specifically, the new name contained in this work is available under the

172 ICZN from the electronic version of this article. Both the nomenclatural acts and the published

173 work itself are registered in ZooBank, the online registration system for the ICZN. The ZooBank

174 Life Science Identifiers and the associated information can be viewed online by appending the

175 LSID to the prefix "http://zoobank.org/" in any web-browser. The LSID for this publication is:

176 urn/lsid/zoobank.org/pub/95CFDD42-D8DB-4DC7-BFB3-5B34CCC6508C

177

178 Results

179 1. Systematic paleontology

180 MAMMALIA Linneaus, 1758

181 CETACEA Brisson, 1762

182 PELAGICETI Uhen, 2008

183 NEOCETI Fordyce \& de Muizon, 2001

184 MYSTICETI Gray, 1864

185 PLICOGULAE Geisler et al. 2011

186 PAN BALAENOPTEROIDEA (NCN) (panstem-based version of Balaenopteroidea Gray 1868) 
187 Norrisanima, nov. gen., file://localhost/urn/lsid/zoobank.org/act/E777170E-03BC-40AA-A04B-

188 65CE92C956BD

189

190

191 Definitions: 'Pan-Balaenopteroidea' refers to the panstem that includes crown Balaenopteroidea

192 (CCN), and all other lineages closer to Balaenoptera Lacépède, 1804

193 than to Caperea Gray, 1864, such as Pelocetus calvertensis Kellogg, 1965, Norrisanima

194 miocaena (Kellogg, 1922) and Parabalaenoptera bauliensis Zeigler et al. 1997. Crown group

195 Balaenopteroidea refers to the crown clade arising from the last common ancestor of

196 Eschrichtius and all named extant species of Balaenoptera. Given the potential paraphyly of both

197 the family Balaenopteridae and the genus Balaenoptera (see Introduction), we elect not to

198 formalize crown concepts for these aforementioned taxonomic groups within Balaenopteroidea

199 at this time.

200

201 Type and only known species: Norrisanima miocaena (Kellogg 1922), new combination

202

203 Etymology: Combining the surname Norris and the Latin anima (breath of life), the generic

204 name honors the late Dr. Kenneth S. Norris and his son, Dr. Richard D. Norris, for their

205 contributions to the natural history of California, marine mammalogy, and evolution in the

206 marine realm. Aside from the holotype specimen's provenance from southern California, the

207 epithet also honors the teaching and mentorship legacies of both Norrises at various campuses of

208 the University of California, including the Scripps Institution of Oceanography, where R. D.

209 Norris served on MSL's doctoral dissertation committee. 
211 Diagnosis: Same as that of the only known species Norrisanima miocaena, new combination

212 Figs 2-8;S1-S6.

213

214 Age: Same as that of the only known species.

215 Norrisanima miocaena, new combination, LSID: urn:Isid:zoobank.org:act:E777170E-03BC-

216 40AA-A04B-65CE92C956BD

217

218 Diagnosis: N. miocaena is a stem balaenopteroid that possesses the following autapomorphies:

219 the lateral margins of the nasal are parallel; spreading of the anterolateral portion of the parietal

220 on to the posteromedial corner of the supraorbital process of the frontal; the anteriormost point of

221 the supraoccipital in dorsal view is in line with the anterior half or anterior edge of the

222 supraorbital process; the zygomatic process of the squamosal is distinctly higher dorsoventrally

223 than wide transversely; having a squared anterior apex of the supraoccipital shield; the tip of the

224 postglenoid process pointing ventrally in lateral view, lacking a distinct ridge delimiting the

225 insertion surface of tensor tympani on medial side of the anterior process of the periotic; and

226 having a superior process of the periotic present as a distinct crest forming the lateral wall of the 227 suprameatal fossa.

228

229 Holotype: USNM 10300 is an incomplete cranium, including both tympanoperiotics as isolated 230 material, an isolated lumbar vertebra, a disarticulated fragment of the vomer, and single non-

231 phalanx fragment of the manus. Kellogg (1922) reported that the anterior portion of the rostrum

232 and much of the right side of the skull were damaged or destroyed during excavation. In 
233 addition, the palatines were damaged during transport to the Smithsonian Institution. Additional

234 plaster has been added since the original description — particularly to hold parts of the right side

235 of the cranium (squamosal, including the zygomatic arch, and maxilla) together. The

236 disarticulated vomer fragment has no patent connections with the cranium. The right tympanic

237 bulla was also damaged, but most of the fragments were recovered and reconstructed. The right

238 periotic is missing its posterior process but is otherwise complete.

239

240 Type Locality: The main Celite quarry of the Lompoc diatomite mines (after the Celite

241 Corporation), also called the Johns-Manville quarry (after the Johns-Manville Company), near

242 Lompoc, California, U.S.A. Kellogg (1922) described the type locality as "one-half mile

243 northwest of the northeast corner of township 6 north, range 34 west (Lompoc Quadrangle), on

244 top of divide between drainage of San Miguelito Creek and Salsipuedes Creek, 3 miles south and

245 east of Lompoc, Santa Barbara County, California." Using Google Earth and the current Lompoc

246 Hills Quadrangle map (USGS NGA Ref No: X24K26325), which includes the township 6

247 borders, the approximate GPS coordinates for the excavation site are $34^{\circ} 36^{\prime} 56^{\prime \prime} \mathrm{N} ; 120^{\circ} 26^{\prime} 43^{\prime \prime}$

$248 \mathrm{~W}$ with a margin of error of approximately 0.5 miles. The Celite quarry mentioned for the type

249 of Norrisanima is equivalent to the Johns-Manville quarry (see Dibblee, 1950), but separate from

250 the nearby Great Lakes Carbon Corporation quarry (which is the type locality of the fossil

251 odobenid Imagotaria downsi Mitchell, 1968) and very likely separate from Celite Quarry No. 9,

252 which is the type locality of the fossil crown otariid Pithanotaria starri Kellogg, 1925; see

253 Repenning and Tedford (1977).

254

255 Formation: Monterey Formation. 
257 Age: Late Tortonian, between 7.6-7.3 Ma. Kellogg (1922) reported that the type specimen was

258 discovered by quarrymen at the Celite Products Company (now Celite Corporation, or generally

259 Celite) diatomite mines in Lompoc, California, in a horizon “about 150 feet below the quarry's

260 surface" at the type locality. Kellogg (1922) noted, at the time, that a precise determination of the

261 type specimen's stratigraphic origin would not be possible until the quarry deepened to that latter

262 depth; to our knowledge, this determination never happened. At the time of Kellogg (1922)'s

263 description, Kellogg correlated the Lompoc diatomite mines with the Temblor Formation

264 (roughly middle to late Miocene), while work throughout the $20^{\text {th }}$ century eventually assigned

265 the Lompoc diatomites to the Monterey Formation. Relying on work by Kleinpell (1938) and

266 Barron (1986), Behl and Ramirez (2000) reported a late Miocene age for the Lompoc diatomites

267 between 8.5-5.5 Ma (Late Tortonian to Messinian). Later, Barron and Isaacs (2001) revised the

268 age of the Lompoc diatomites to 9.2-6.8 Ma, based on a detailed chronostratigraphic framework

269 of the Monterey Formation. Deméré et al. (2005) argued that the Lompoc diatomites should be

270 Tortonian in age (8.2-7.3 Ma), following Chang and Grimm (1999). Marx and Fordyce (2015)

271 cited Chang and Grimm (1999)'s upper age boundary of $7.3 \mathrm{Ma}$ on the $218 \mathrm{~m}$ sequence of

272 mineable diatomite exposed at the Celite quarry (reported to Chang and Grimm (1999) as "J. A.

273 Barron, pers. comm., 1997”) along with unpublished data from N. Kohno (pers. comm. to Marx

274 and Fordyce (2015), in 2010), who assigned diatoms collected from the matrix surrounding the

275 cranium of N. miocaena to the Rouxia californica diatom subzone (NPD7A) of Akiba (1986).

276 The NPD7A subzone now ranges across the current boundaries of the Tortonian and Messinian

277 with an age range of 7.6-6.5 Ma (see Barron et al. 2001), with the older age providing a lower 
278 age bound. Thus, Marx and Fordyce (2015) argued that the preponderance of evidence points to

279 a 7.6-7.3 Ma age (latest Tortonian) for the type specimen of N. miocaena.

280

281 Comments: Fossil material from the Funakawa Formation (upper Miocene) of Akita, Japan

282 (Oishi and Hasegawa 1995) and isolated tympanic material from the Tatsunokuchi and Na-arai

283 formations (Lower Pliocene) of northeastern Honshu, Japan have been tentatively assigned to

284 this taxon (Deméré et al. 2005). We have not viewed this material and therefore cannot comment 285 on its affinity.

286

287

288 Description

289

290 Cranium (Figs. 2-4;7;:S1-S2)

291 Premaxilla

292 In dorsal view, the premaxilla is exposed along the mesorostral groove, then narrows posteriorly.

293 The left premaxilla is fragmented into a sharp point anteriorly with a medial deflection so that its

294 medial margin extends posterior to its lateral margin, terminating at about the level of the

295 anterior margin of the nasal. The ascending process of the premaxilla is incomplete where it

296 abuts the left nasal, leaving an open suture. We suspect that, in life, the ascending process of the

297 maxilla likely would have abutted or overlapped the ascending process of the premaxilla near the

298 nasal. Finally, the premaxilla is situated dorsally above the maxilla, so the rostrum slopes

299 ventrally toward the lateral margin.

300 


\section{Maxilla}

302 The right maxilla is damaged and almost entirely lost; the anterior section of the left maxilla is

303 damaged and lost. The posterior portion of the ascending process of the left maxilla appears to be

304 lost as well, revealing a slight depression lateral to the left nasal. In dorsal view, both the medial

305 margin of the maxilla is parallel with the sagittal plane, while the lateral margin of the maxilla

306 diverges posterolaterally. The medial margin of the maxilla has a slight concavity, whereas the

307 preserved lateral margin appears straight. Overall, the maxilla broadens posteriorly where it

308 transitions to the rest of the cranium. In the posteromedial corner of the maxilla broadens with an

309 ascending process of unknown shape, although the process does extend medially towards the

310 premaxilla and the parietal - the degree of overlap or interdigitation cannot be distinguished

311 based on the preservation. Similarly, we cannot ascertain, with any degree of confidence, the

312 articulation and sutural configuration of the ascending process of the maxilla and the anterior

313 extent of the parietal at this part of the vertex, where the overall topography curves

314 ventrolaterally from dorsal height of the nasals. At the lateral margin, the maxilla lies ventral to

315 the frontal creating a shallow antorbital notch. In anterior view, the maxilla is elevated dorsally

316 at the medial margin where it contacts the premaxilla and descends ventrally at the lateral

317 margin. The poor preservation of the maxilla prevents determination of any dorsal infraorbital

318 foramina.

320 In ventral view, the lateral margin of the maxilla is parallel with the sagittal plane until it deflects

321 laterally, slightly anterior to the anterior margins of the frontals. The medial margin of the

322 maxilla is damaged, but can clearly be seen underlying the vomer. The posterior margin of the

323 maxilla is also fragmented, making it difficult to discriminate an infraorbital plate. Medially, the 
324 posterior margin underlies the palatine. The posteromedial corner of the maxilla is poorly

325 preserved. Clear foramina and palatal sulci are present along the whole ventral surface of the

326 maxilla on the rostrum, likely representing the presence of the neurovasculature to support

327 baleen in life. Posteriorly, the foramina and palatal sulci angle posterolaterally, and angle

328 increasingly lateral moving anteriorly. A triangle-shaped trough lies at the posterolateral corner

329 of the maxilla, anteroventral to the preorbital process of frontal (this feature is visible in other

330 extant balaenopteroids). The two maxillae would likely have contacted each other at the midline

331 (possibly with the anterior portion of the vomer visible near the mesorostral groove), but we

332 cannot be certain because of the missing portion of the right maxilla.

333

334 Nasal

335 Overall the nasal is short and rectangular, being slightly longer anteroposteriorly than

336 transversely wide. In dorsal view, the left nasal is complete and in its original articulation, but

337 the ascending process of the left premaxilla is missing, leaving a gap between the ascending

338 process of the maxilla and the left nasal. The posterior margin of the nasal abuts the anterior

339 margin of the supraoccipital. The anterior margin curves anteriorly at the lateral corner. An

340 anterolateral projection parallels the premaxilla and creates the posterolateral border of the

341 mesorostral groove. Together, the anterior margins of both nasals overall slope anteroventrally,

342 descending into the mesorostral groove.

344 Palatine

345 In ventral view, the anterior portion of the palatine is fragmented and it was difficult to

346 determine a clear anterior suture with the maxilla. The lateral margin of the palatine wraps 
347 dorsally, and forms the medial margin of the frontal. It is unclear if the posterior margin of the

348 palatine contacts the pterygoid. The palatine slopes ventrally toward the midline where it

349 underlies the vomerine crest.

350

351 Vomer

352 In ventral view, the vomerine crest appears below the palatine at the level of the distal opening of 353 the orbital canal. It rises ventrally as it progresses posteriorly and extends under the basisphenoid

354 to the level between the basioccipital crests. At its visible anterior end in the basicranium, the

355 vomer is transversely swollen and narrows posteriorly to form a rounded ridge. The surfaces of

356 the vomer that line the internal choanae are damaged anteriorly, but the shape is clear, with

357 anterior portions that are wide relative to the posterior end, and terminate near the pterygoid-

358 basioccipital suture, anteromedial to the bulbous portion of the basioccipital crests, which form

359 ventrally deflected troughs between each basioccipital crest and the vomerine crest. Posteriorly,

360 the nasal plate of the vomer forms the floor of the basisphenoid.

361

\section{Frontal}

363 In dorsal view, the frontal is broadly rectangular with the lateral and medial margins shorter than

364 the anterior and posterior margins. The anterior margin of the frontal appears to abut the maxilla

365 in a broadly transverse in orientation, although the exact contact between the two element is

366 obsure because of poor preservation. Along the lateral margin, the contact between the lateral

367 process of the maxilla and the front is clear, suggesting a similar transverse orientation as in

368 other balaenopteroids. In a lateral view the frontal shows a patent but shallow depression of

369 maxillofrontal suture that Deméré et al. (2005) termed an "incipient balaenopterid "pocket," 
370 although this structure in other rorquals is largely a construction of more of the maxilla rather

371 than the frontal. The poor preservation again precludes speculation about its original

372 morphology. In oblique dorsolateral view, the medial margin of the frontal may contact the

373 parietal just before the parietal rises to the vertex, excluding the frontal's participation in the

374 vertex. The true sutural contacts of this relationship are unclear, and we leave the interpretation

375 of this part of the vertex open to further work.

376

377 The preorbital process of the frontal is directly posterior to the lateral process of the maxilla. The

378 postorbital process of the frontal extends slightly further laterally relative to the anteroposterior

379 leve of the preorbital process. The medial margin of the frontal near the temporal wall is dorsally

380 elevated so that the lateral margin slopes ventrally. Posteriorly, the postorbital ridge frontal is

381 robust and dorsoventrally thickened.. Beginning with the contact between the postorbital process

382 and the zygomatic process of the squamosal, a blunt ridge on the dorsal surface of the frontal

383 extends anteromedially to about the level of the antereoposterior middle of the orbit. In life, this

384 ridge likely demarcated the lateral marginfor the surface of origin for the temporalis muscle.

385

386 In ventral view, the anterior margin of the frontal appears to have a transverse suture with the

387 maxilla overriding it, although poor preservation makes it difficult to ascertain the extent of

388 infraorbital plate of the maxilla overlying the maxillofrontal suture. Medially, the ventral surface

389 of the frontal borders the palatine. The optic canal is deeply concave with posterior and anterior

390 margins (medially) that are dramatically curved ventrally, with the two edges almost touching

391 ventromedially. The preorbital process points anteroventrally, but does not underlie the maxilla. 
392 The postorbital process contacts the zygomatic process of the squamosal. No jugal or lacrimal

393 are preserved.

394

395 Parietal and Alisphenoid

396 In dorsal view, near the vertex, the parietal appears to be exposed at the vertex ventralolateral to

397 the supraoccipital, and possibly in confluence with the medioposterior end of the ascending

398 process of the maxilla. Poor preservation prevents a specific discrimination of the parietal in this

399 region. The presence of an interparietal cannot be determined. Posterior of the level of the vertex,

400 the lateral exposure of the parietal broadens below the overhanging nuchal crest and dorsomedial

401 to the frontal; the parietal appears patent both in the vertical wall descending from the nuchal

402 crest to the frontal, and spreads, in fan shape orientation, along the posteromedial corner of the

403 supraorbital process of the joining with the vertical surface of the same element at nearly $90^{\circ}$

404 angle. The surface of the parietal in the temporal wall is somewhat obscured by poor

405 preservation, but basic sutures can be identified. In lateral view of the wall, the parietal narrows

406 posteriorly, pinching past the posterior extent of the frontal then dorsoventrally expands greatly

407 in the temporal wall where it forms a sigmoidal suture with the squamosal, at the posterior

408 margin of the temporal fossa.

409

410 The alisphenoid is visible in the temporal wall vental to the posteromedial corner of the

411 postorbital ridge of the supraorbital process of the frontal. In the temporal wall, the alisphenoid

412 appears as a trapezoidal window, dorsal to the pterygoid; the squamosal contacts the posterior

413 margin while the parietal contacts the alisphenoid's entire dorsal margin. 


\section{Supraoccipital}

416 The sutures between the supraoccipital, exoccipital, and basioccipital are tightly ankylosed. In

417 dorsal view, the general shape of the supraoccipital is neither triangular nor circular, but

418 trapezoidal with a lightly squared-off anterior margin. The lateral margins diverge slightly

419 laterally in the posterior two thirds. The anterior of supraoccipital shield passes anterior of the

420 levels of the frontal and parietal, abutting the nasals anteriorly at the vertex. It is relatively flat

421 topographically, with no sagittal crest or obvious foramina or sulci. The nuchal crest comprises

422 the lateral border of the supraoccipital at the supraoccipital-squamosal suture where it rises

423 anteromedially as the continuation of the mastoid crest of the squamosal.

\section{Exoccipital}

426 In ventral view, there is a gentle posterolateral deflection of the exoccipital. In lateral view, the

427 paroccipital process is dorsoventrally aligned, flat (i.e., not tilted), and thickened

428 anteroposteriorly. The posterior surface of the paraoccipital reaches posteriorly the level of the

429 occipital condyles. In posterior view, the occipital condyles are reniform in shape and

430 transversely broader ventrally than dorsally; dorsal condyloid foramina are present on both sides.

431 The occipital condyles are large relative to the basiocciptal crests and lay nearly in a dorsoventral

432 plane, with lateral margins strongly convex and medial margins straight. There is a narrow

433 ventral intercondylar notch and a broad dorsal intercondylar notch.

\section{Basioccipital}

436 In ventral view, the anterior margin of the basioccipital may be slightly partially obscured by the 437 nasal plate of the vomer. The lateral margins of the basioccipital form the medial margins 
438 pterygoid sinus fossa, while the ventral surface of the basioccipital is flat between the 439 basioccipital crests. The crests are massive and rounded (i.e., bulbous). The bone overlying the 440 jugular notch, which is deflected laterally at a $45^{\circ}$ angle from the midline, is robust and nearly 441 forms an arch.

442

\section{Squamosal}

444 The squamosal is robust medially at the position of the mastoid crest where it abuts the 445 supraoccipital and exoccipital, and pinches and slants anteroposteriorly as it extends 446 anterolaterally becoming the zygomatic process. In dorsal view, the anterolateral margin of the squamosal visibly forms the posterior margin of the temporal fossa. Medially, this line moves

448 into the temporal wall. In ventral view, the squamorsal borders the pterygoid to form the lateral 449 border of the pterygoid sinus fossa, along the ventral margin of the temporal fossa.

451 In ventral view, the squamosal has a laterally expansive and deep glenoid fossa, with a large and 452 slightly bulbous postglenoid process. The postglenoid process extends more ventrally than 453 posteriorly, but has an anterior hook at the lateral margin that slightly encloses the glenoid fossa 454 laterally and posteriorly. In lateral view, the anterior margin of the squamosal is more 455 dorsoventrally oriented than anteroposteriorly. The postglenoid process is the most ventral 456 portion of the cranium far below the ventral plane of the basioccipital crests. In posterior view,

457 the nuchal crest becomes the mastoid crest at about the level of the dorsal termination of the 458 occipital condyles.

459 
460 The zygomatic process is anteroposteriorly short but dorsoventrally robust and contacts the

461 postorbital process of the frontal. The zygomatic process is taller dorsoventrally than it is

462 transversely wide or anteroposteriorly long. Its overall axis has an anterolateral deflection and is

463 not straight anteroposteriorly. The ventral anterior portion of the right zygomatic process is

464 damaged, but the reconstruction from the early $20^{\text {th }}$ century preserves the overall relationship and

465 distance to the postorbital process of the frontal..

466

\section{Pterygoid}

468 In ventral view, the pterygoid sinus fossa is a large and deep renal-shaped cavity that tapers

469 slightly posteriorly. The roof of the pterygoid sinus fossa is overlain and enclosed

470 posterodorsally by the squamosal. The medial surface the pterygoid forms the lateral surface of

471 the internal nares; the pterygoid hamulus is missing, likely from a break. The lateral surface of

472 the pterygoid rises from the pterygoid fossa and contributes to the temporal wall.

473

474 Tympanic Bulla (Figs. 5; S4)

475 In dorsal view, the tympanic bulla has an overall rectangular shape. It has a slightly pear-shaped

476 medial margin resulting from a shallow median furrow. The posterior edge has rounded

477 prominences (the medial prominence is transversely broader) separated by a shallow

478 interprominential notch. The medial posterior prominence has a rounded transition to the medial

479 margin of the bulla, whereas the lateral posterior prominence transitions to the lateral margin at a

480 sharp angle. The anterior margin is relatively flat, and the lateral surface is slightly convex

481 anteriorly, before transitioning to a pronounced lateral deflection at the level of the sigmoid

482 process. As a result, a deep lateral furrow separates the middle portion from the anterior portion. 
483 Continuing posteriorly from the sigmoid process, the lateral margin is straight in the sagittal 484 plane.

485

486 The eustachian notch is broad and directed medially. The anterior portion of the outer lip is

487 broken so the anterior pedicle is not present. The sigmoid process is poorly preserved and

488 separate from the body of the bulla, but a contact can be inferred. It originates posterior from the

489 level of the lateral furrow and overlays the tympanic cavity with a posterior deflection. The

490 posterior pedicle is not preserved. The involucrum is transversely broad posteriorly and narrows

491 anteriorly. Posteriorly it is smooth, but there are anterior transverse creases emanating from the

492 eustachian notch.

493

494 In ventral view, the surface of the tympanic is relatively smooth throughout the body of the bulla, 495 except the medial margin where rugose pitting is visible. Although there is some damage to the 496 outer lip, the anterolateral corner is inflated, creating a distinct lobe bound posteriorly by the 497 lateral furrow. There is no anterolateral shelf.

498

499 In lateral view, the bulla is somewhat ovoid. The anterior margin is dorsoventrally aligned and 500 transitions gently into the smooth convex ventral margin. The ventral margin ends abruptly at the 501 lateral posterior prominence and angles sharply anterodorsally as it becomes the posterior 502 margin. In lateral view the posterior deflection of the sigmoid process is readily apparent, such

503 that it extends posterior to the conical process. An elongate projection of the sigmoid process is 504 preserved, but not modeled because it is a separate fragment, free from articulation with the rest 
505 of the bulla. Anterior to the sigmoid process, the conical process is preserved as a blunted peak.

506 Damage to the lateral surface prevents interpretation of the mallear ridge and sigmoidal cleft.

507

508 In medial view, the involucrum is massively globular posteriorly and narrows anteriorly. The

509 involucral ridge is shallow, and oriented anteroposteriorly with a very slight ventral convexity.

510 This ridge is nearly parallel to the main ridge and separated from it by a band of rugose and

511 deeply pitted bone. The medial posterior prominence is bulbous and smooth with a

512 dorsoventrally straight posterior margin. The median furrow has a slight anterior bulge.

513

514 Periotic (Figs. 6; 8; S3)

515 Of the two periotics preserved in the type specimen, the left periotic is better preserved and

516 provides the basis for the following description. In dorsal view, the periotic is roughly L-shaped,

517 and consists of a triangular anterior process and two medial projections of the pars cochlearis.

518 The posterolateral angle of the periotic is the triangular flange of the lateral tuberosity; the

519 posterior processes of both periotics are fused with the posterior processes of the tympanic

520 bullae, and they remain preserved in situ with the cranium. The lateral border of the anterior

521 process is rounded anteriorly, while the medial edge is dorsoventrally oriented. The most lateral

522 portion of the periotic is an inflated lateral margin of the anterior process. The posterior edge of

523 the pars cochlearis exhibits a shallow concavity, bordered laterally by the level of the caudal

524 tympanic process. The external anterior margin of the anteriormost of the two projections of the

525 medial extension of the pars cochlearis is straight and medially oriented. The internal margin of

526 this projection is rugose. The posterior projections follows the same aspect but it is not as long in

527 the medial direction. 
529 In ventral view, the anterolateral sulcus is present and follows an anteroposterior direction offset

530 laterally from the anterior tip of the anterior process. The medial margin of the anterior process is

531 sinusoidal and terminates posteriorly near the level of the hiatus fallopii. The facial sulcus wraps

532 posterolaterally around the base of the smooth surface of the cochlea. The posteromedial

533 termination of the facial sulcus is ventral to, and obscures, the opening of the fenestra ovalis near

534 the triangular flange of the lateral tuberosity. The opening of the fenestra ovalis is occupied by a

535 relatively large stapes in articulation.

536

537 In medial view, the periotic appears as two distinct sections, the anterior process (which is

538 roughly conical is shape) and the pars cochlearis (which appears roughly spheroid with a

539 posterior projection off the posterodorsal corner - the lateral ridges of the triangular flange of the

540 lateral tuberosity. The internal auditory meatus is located roughly between the two major

541 projections extending medially from the pars cochlearis. Many of the features of the internal

542 auditory meatus and the area surrounding it are indicative of an ontogenetically mature

543 individual, especially relative to the work of Ekdale et al. (2011) on ontogenetic changes in the

544 shape and depth of the internal auditory meatus in M. novaeangliae. These traits include: 1) a

545 nearly circular shared aperture for both the facial canal (CNVII), and 2) the vestibulocochlear

546 aqueduct (CNVIII) separated by a deeply recessed crista transversa. The crista transversa runs

547 relatively straight anteroposteriorly with the facial canal on the ventral side and the

548 vestibulocochlear canal on the dorsal side. Posterior to the internal auditory meatus is the

549 recessed and dorsoventrally elliptical opening of the perilymphatic and endolymphatic foramina. 
551 In lateral view, the periotic is flat along the dorsal margin aside from a concavity near the

552 posterior half of the anterior process. The ventral margin of the anterior process is also relatively

553 flat and terminates posteriorly at the cochlea. The cochlea protrudes ventrally quite abruptly

554 before curving posteriorly and then sloping back toward the dorsoposterior corner.

555

556

557 Discussion

558 Norrisanima compared with crown balaenopteroids

559 In recent phylogenetic analysis of mysticetes using morphological and molecular data, Marx and

560 Fordyce (2015) and Slater et al. (2017) showed Norrisanima represented a lineage positioned

561 well outside of crown Balaenopteroidea, unrelated to species in the extant genus Balaenoptera,

562 Eschrichtius, and not sister to M. novaeangliae. The morphological partition of Slater et al.

563 (2017)'s analysis (which was based data from Marx \& Fordyce, 2015) shows seven

564 synapomorphies that diagnose crown Balaenopteroidea: 1) a straight posterior border of the

565 supraorbital process in dorsal view; 2) a short postorbital process that does not markedly project

566 in any direction; 3 ) an optic canal that in ventral view is enclosed medially by bony laminae; 4) a

567 well-developed and thickened postorbital ridge along the medial portion of the optic canal; 5)

568 flattened dorsal surface of the nasal bones; 6) inflated posterior corner of the pars cochlearis

569 (medial to the fenestra rotunda) that extends posteriorly beyond the fenestra rotunda; and 7)

570 absent or indistinct medial lobe of the tympanic bulla. Norrisanima exhibits only one of these

571 seven synapomorphies: the flattened nasal bones. This trait is a marked departure from the

572 rounded condition of some stem mysticetes; and some crown mysticetes (and even Balaenoptera

573 spp.) that exhibit nasals with a peak or crest extending to the midline. Although there is no right

Peer) reviewing PDF | (2018:07:29605:2:2:NEW 26 Jul 2019) 
574 nasal in the holotype of Norrisanima, the left nasal is clearly flat and only curves ventrally at the

575 anterior-most margin as it dives into the mesorostral groove.

576

577 The other six traits separate Norrisanima from crown Balaenopteroidea. Instead of a straight

578 posterior edge of the supraorbital process, Norrisanima has a slightly concave margin. Like

579 crown Balaenopteroidea, Norrisanima does have a short postorbital process, but it is deflected

580 posteriorly instead of laterally as in crown balaenopteroids. The medial portion of the optic canal

581 is open ventrally in Norrisanima, although anterior and posterior margins of the optic canal do

582 extent ventrally toward the medial end of the canal, and are almost touching. This state in

583 Norrisanima appears to be somewhat intermediate between stem and crown balaenopteroids,

584 which have closed optic canals medially. Norrisanima clearly has a postorbital ridge, but it is not

585 as thick as modern rorquals, nor does it displace the optic canal from the posterior border of the

586 supraorbital process as in extant balaenopteroids.

587

588 Broadly, the entire vertex of Norrisanima is very reminiscent of crown balaenopteroids,

589 especially large species in the genus Balaenoptera, such as Balaenoptera musculus Linnaeus,

5901758 and Balaenoptera physalus (Fig. 6). In both of these latter species, the nasals and ascending

591 processes of the premaxillae meet the anterior margin of the supraoccipital shield in a transverse

592 line that is nearly rectilinear for all the element terminations involved (unlike, for example, the

593 posterior pinching of the nasals in B. acutorostrata Lacépède, 1804). However, in Norrisanima,

594 the position of this configuration of the vertex relative to the level of orbit is most similar to $B$.

595 acutorostrata, nearly at the midway level between the pre- and postorbital processes of the

596 frontal. The outline of the nasal in dorsal view in Norrisanima, in particular, shares broad 
597 rectangular features with Eubalaena australis (Desmoulins, 1822) and an anterolateral spur

598 similar to the one found in some specimens of B. edeni Anderson 1878 (see Omura et al. 1981). 599

600 The tympanoperiotics of Norrisanima show two traits that are not shared with crown 601 balaenopteroids, although the differences are subtle (Fig. 7). For example, the pars cochlearis is 602 less globular and inflated in Norrisanima than in crown balaenopteroids (Ekdale et al. 2011).

603 Also, medial to the fenestra rotunda, Norrisanima exhibits a raised, inflated surface reminiscent, 604 in miniature, of the involcrum on the tympanic bulla; this inflated surface is absent in members 605 of the genus Balaenoptera (Ekdale et al. 2011). Also, crown balaenopteroids do not have a 606 medial a lobe on their tympanic bulla, or this medial lobe is indistinct. Norrisanima has a medial 607 lobe on the bulla that is equal in size to the lateral lobe.

608

609 Because of the taxonomic legacy of this specimen, we further compared Norrisanima with 610 Megaptera and Balaenoptera spp., focusing on the periotics, which possess a large number of 611 diagnostic cetacean traits (Ekdale et al. 2011). This process was performed in two stages: first, 612 we compared Megaptera and Balaenoptera to develop a list of traits in which the two generally 613 differ; then we compared Norrisanima to each genus within the context of these traits. These 614 traits are not meant to be diagnostic nor exhaustive, and are merely heuristic; Norrisanima is 615 formally diagnosed above according to previous phylogenetic analyses, not using this set of 616 traits.

617

618 In comparisons between extant Megaptera and Balaenoptera, we found ten characters that 619 broadly distinguish the two genera (listed in Table 1). Megaptera periotics broadly differ from 
620 other Balaenoptera periotics in ten features, including: (1) the apertures of the cranial nerve

621 ducts erupt in a deep recess in the medial margin of the pars cochlearis; (2) the apertures of the

622 cranial nerve ducts open medially, without a dorsal deflection found in Balaenoptera; (3) a

623 dorsoventrally flattened and mediolaterally elongate pars cochlearis; (4) a short and robust

624 anterior process relative to the size of the pars cochlearis; (5) a lateral crest on the ventral surface

625 of the anterior process; (6) a sharply pointed triangular flange of the lateral tuberosity; (7) a

626 posteriorly deflected triangular flange; (8) a concave medial margin of the pars cochlearis (in

627 dorsal and ventral view); (9) a transverse ridge on the ventral surface of the pars cochlearis; and

628 (10) a deep invagination of the fenestra ovalis that almost completely obscures the stapes in

629 ventral view.

630

631 Norrisanima shares six traits with Megaptera and four with Balaenoptera (Table 1). The six

632 traits shared with Megaptera include: (1) the apertures of the cranial nerve ducts erupt in a deep

633 recess in the medial margin of the pars cochlearis; (2) the apertures of the cranial nerve ducts

634 open medial, without a dorsal deflection; (3) a dorsoventrally flattening and mediolaterally

635 elongation of the pars cochlearis; (4) a short and robust anterior process relative to the size of the

636 pars cochlearis; (5) a concave medial margin of the pars cochlearis (in dorsal and ventral view);

637 and (6) a deep invagination of the fenestra ovalis that almost completely obscures the stapes. The

638 four traits that Norrisanima shares with Balaenoptera include: (1) the lack of a lateral crest on

639 the ventral surface of the anterior process; (2) a rounded pointed triangular flange of the lateral

640 tuberosity; (3) a laterally deflected triangular flange; and (4) the lack of a transverse ridge on the

641 ventral surface of the pars cochlearis.

642 


\section{Comparisons with other fossil mysticetes}

644 As a stem balaenopteroid, the holotype specimen of Norrisanima shares some similarities with 645 other stem balaenopteroids and fossil mysticetes of similar age, including 'Balaenoptera' siberi 646 Pilleri, 1989 (also see Pilleri 1990), 'Megaptera' hubachi Dathe, 1983 and Incakujira 647 anillodefuego Marx and Kohno, 2016. The proximal end of the rostrum of Norrisanima is similar 648 to all of these taxa, although the incompleteness of the type specimen makes comparisons 649 difficult; indeed few fossil balaenopteroid taxa (either crown or stem) preserve the entire rostral 650 margin intact. The lateral process of the maxilla in Norrisanima is not a perpendicular deflection 651 as in Protororqualus cuvieri (Bisconti, 2007b), but about $120^{\circ}$ from the midline, more like 652 Incakujira, 'B.' siberi, and Plesiobalaenoptera quarantellii (Bisconti 2010a).

654 The overall shape of the nasal in Norrisanima is somewhat similar to 'B. ' siberi, 'M.' hubachi 655 Bisconti, 2010b and Protororqualus cuvieri Bisconti, 2007b, but the laterally even and 656 rectilinear nasal outlines of Norrisanima are unique; all other stem and crown balaenopteroids 657 have nasals that taper posteriorly. On the dorsal surface of the nasal, Norrisanima possesses an 658 anterolateral flange similar, but longer, than those present in B. edeni (Omura et al. 1981). In 659 dorsal view, Archaebalaenoptera castriarquati Bisconti, 2007a has an anterolateral corner of the 660 nasal that exceeds the anterior level of the anteromedial corner, but there is no flange as in 661 Norrisanima. Although somewhat incomplete, the remains of what appears to be a relatively 662 thick premaxilla near the anterior termination of the nasals in Norrisanima is similar to that 663 found in small to mid-sized Balaenoptera spp., such as B. acutorostrata and B. edeni, and less

664 like the thinner terminations in Archaebalaenoptera, Incakujira, Parabalaenoptera, 665 Protororqualus, 'M.' hubachi, and Nehalaennia devossi Bisconti et al. 2019. 
666

667 The medial surface of the supraorbital process of the frontal does not slope to the vertex as in 668 true cetotheriids, such as Joumocetus shimizui Kimura \& Hasegawa, 2010 although it is not as

669 sharply tabular, where the vertex is stepped above the level of the frontal, as in 'B.' siberi,

670 Incakujira, and Balaenoptera spp. Generally, the vertex in Norrisanima is transversely wide

671 (relative to the length of the nasals) compared to Archaebalaenoptera, Incakujira,

672 Parabalaenoptera, Protororqualus, and even ' $M$.' hubachi. The dorsal junction of the maxilla

673 and frontal that forms the so-called "balaenopterid pocket" (Deméré et al. 2005) is lightly visible

674 in Norrisanima, apparently to the same degree as in 'M.' hubachi, but certainly not as strongly

675 delineated as in Archaebalaenoptera, 'B. 'siberi, Incakujira, Protororqualus, Nehalaennia, and

676 living Balaenoptera and Megaptera. In dorsal view, the postorbital process of the frontal in

677 Norrisanima is sharply angular and notably overlays the zygomatic process of the squamosal;

678 this combination of features is clear in Incakujira, slightly overlapping in ' $M$.' hubachi, but

679 notably absent in other stem balaenopteroids with complete supraorbital processes of the

680 frontals, such as Parabalaenoptera.

681

682 In dorsal view, Norrisanima shares the overlap of the parietal on to the posteromedial corner of

683 the supraorbital process of the frontal with other stem balaenopteroids such as B. bertae,

684 Protororqualus, Nehalaennia, and to a small degree Archaebalaenoptera, but not Incakujira, and

685 other crown balaenopteroids. It appears that "Balaenoptera" ryani Hanna and McLellan 1924

686 also possessed such overlap (as in Norrisanima); as Deméré et al. (2005) pointed out, the type

687 and only specimen of this taxon requires a redescription and likely a new generic name.

688

Peer] reviewing PDF | (2018:07:29605:2:2:NEW 26 Jul 2019) 
689 In Norrisanima, the anterior margin of the supraoccipital shield is essentially at the level of the

690 preorbital process, in dorsal view, which is broadly similar to living Megaptera and B.

691 acutorostrata, but unlike all other living Balaenoptera spp. The position of this margin in

692 Norrisanima is anterior to most other stem balaenopteroids, where it is shifted more posteriorly,

693 as in 'M.' hubachi, Parabalaenoptera, 'B.' siberi, Nehalaennia, Balaenoptera bertae

694 Boessenecker, 2012 and Incakujira. Also, the shape of this margin in Norrisanima is broadly

695 semi-lunar with notable angularity resulting in a slight rectangular profile, not sharply acute as in

696 Nehalaennia, Incakujira, Parabalaenoptera, and B. bertae, or with the irregular lobate margin as

697 in 'M.' hubachi. The lateral margin of the supraoccipital, extending to the nuchal crests,

698 overhangs the posterior margin of the temporal wall in Norrisanima, as it does in most other

699 fossil balaenopteroids, but not Archaebalaenoptera. In shape and relative position to the frontal,

700 the supraoccipital of Norrisanima shares little with Archaebalaenoptera and Protororqualus. No

701 interparietal is visible in the dorsal vertex of Norrisanima, although it is possible that part of the

702 parietals are exposed along the lateral margins of the vertex; it is difficult to ascertain this feature

703 because of poor preservation.

704

705 The length and lateral deflection of the zygomatic processes of the squamosal in Norrisanima

706 resembles that of living Balaenoptera spp., and especially Megaptera. Like in many fossil

707 balaenopteroids, the postglenoid process and the posterolaterally facing suprameatal fossa are not

708 visible in dorsal view of the basicranium of Norrisanima. The ratio of the width of the

709 paroccipitals, relative to the bizygomatic width, is more like that in Incakujira,

710 Parabalaenoptera and 'M.' hubachi than that in living Balaenoptera and Megaptera. The entire

711 ventral side of the basicranium in Norrisanima is broadly proportioned like living Balaenoptera 
712 and Megaptera, matching the distance between the glenoid fossa to the pterygoid sinuses, and

713 the anteroposterior length across the observable space formed by the temporal fossa in this view.

714 Although the type specimen of Norrisanima lacks a mandible, the glenoid fossa is broadly

715 similar to extant rorquals, suggesting some basis for inferring lunge-feeding features in this

716 taxon, although there are important soft tissue features that lack osteological correlates to

717 strengthen this argument.

718

719 Lastly, we calculated an estimated total length of Norrisanima at $12.49 \mathrm{~m}$ (using Pyenson \&

720 Sponberg (2011)'s reconstruction equation for stem balaenopteroids). This body size matches

721 that extant gray and sei whales, and is the largest stem balaenopteroid known (see Slater et al.

722 2017). Interestingly, Norrisanima is essentially the same size as the late Miocene to early

723 Pliocene age Eubalaena shinshuensis (12.46 m; Slater et al. 2017), and together these two fossil

724 taxa are larger than any stem mysticete and any crown mysticete outside of crown

725 Balaenopteroidea and crown Balaenidae.

726

727

728 Late Miocene marine mammal assemblages from California and phylogenetic divergence

729 times

730 Norrisanima was collected from late Miocene age diatomite sequences of southern California

731 that have also yielded a variety of large marine vertebrates, including type specimens of the

732 pinnipeds Pithanotaria starri Kellogg, 1925 and Imagotaria downsi Mitchell 1968, and a variety

733 of other seabird and fossil vertebrate taxa. The Tortonian age constraints of Norrisanima (7.6-

$7347.3 \mathrm{Ma}$ ) potentially also apply to Pithanotaria and Imagotaria, which were collected from likely 
735 coeval units of the diatomite sequences with the type locality of Norrisanima, which collectively

736 provide narrower stratigraphic intervals on divergence dates for clades related to these taxa. For

737 example, Pithanotaria is a crown otariid according to recent analyses (Velez-Juarbe 2017), and

738 as the oldest crown lineage, its age constrains the minimum divergence time for this clade.

739

740 Norrisanima's position outside of crown Balaenopteroidea limits its use to constrain the

741 divergence date for crown Balaenopteroidea, although as a late Miocene (Tortonian age)

742 balaenopteroid, Norrisanima is notably older than most other Messinian and Pliocene age fossil

743 balaenopteroids, including all extant and fossil eschrichtiids (see Deméré et al. 2005; Marx \&

744 Fordyce, 2015; Slater et al. 2007). The estimated divergence date for crown Balaenopteroidea is

745 likely older than the late Miocene; McGowen et al. (2009: Table 2, Node 7) provided a

746 comprehensive overview of molecular divergence dates for cetaceans, and calculated a mean

747 Middle Miocene age (13.80 Ma) for the divergence of crown Balaenopteroidea, and largely

748 argued for a 12-10 Ma (later Middle to early Late Miocene) origin timeframe. Geisler et al.

749 (2011) proposed Norrisanima as a preferred fossil calibration point for the minimum divergence

750 age of Plicogulae (i.e., the crown clade formed by Caperea + Balaenoptera). Geisler et al. (2011)

751 indicated a 11.6-7.2 Ma age range for Norrisanima, with a 7.2 Ma date as a minimum age. We

752 propose that this range be narrowed to 7.6-7.3 Ma and the refined age of this taxon would make

753 it more useful for tip-dating calibrations of Plicogulae (see Ronquist et al. 2012).

\section{Conclusions:}

756 Phylogenetically-accurate taxon names that designates between stem and crown taxa are

757 essential for examining the course of evolution giving rise to modern biodiversity. Baleen whales 
758 (clade Mysticeti) embody organismal maxima for many biological traits, but their evolutionary

759 history, including the description of their fossil record, remains a work in progress. Norrisanima

760 miocaena is an extinct species that lacks balaenopteroid synapomorphies as well as all of the

761 autapomorphies of the extant $M$. novaeangliae. Our observations accompany the current

762 phylogenetic framework resulting from broad molecular and morphological datasets, which

763 place N. miocaena outside of crown Balaenopteroidea, and unrelated to the extant humpback

764 whale. By accurately redescribing this species and giving it a new name, we hope to clarify its

765 taxonomy, and — given the updated Tortonian age — provide a constraint for the tip age

766 calibrations of Plicogulae.

767

768

769 Acknowledgements

770 We thank M. Dattoria, J. Conrad, V. Rossi, A. Metallo, and the Smithsonian Institution's

771 Digitization Program Office 3D Lab for training, technical support, and access to equipment. We

772 thank J. Hinton and S. Sholts of the Smithsonian Institution Bio-Imaging Research Center in the

773 Department of Anthropology at the National Museum of Natural History for assistance CT

774 scanning the tympanoperiotic material. We also thank D. Lunde, J. Ososky, and M. R. McGowen

775 for access to the collections in the Division of Mammals in the Department of Vertebrate

776 Zoology at NMNH. MSL thanks the Smithsonian Office of Fellowships and Internships-

777 especially A. Lemon and A. Capobianco — for their assistance during his James Smithson and

778 Secretary's Distinguished Research Postdoctoral Fellowship. NDP thanks the Basis Foundation

779 and its Remington Kellogg Fund for support and J. F. Parham and J. Velez-Juarbe for comments 
780 on the manuscript. Finally, we thank E. Coombs, E. Noirault, A. Goswami, and R. Sabin for 781 access to 3D digital models from the Natural History Museum London.

782

783 Author contributions

784

785

786

787

788

789

790

791

792

793

794

795

796

797

798

799

800

801

MSL, CMP, \& NDP conceived and designed the experiments, performed the experiments, analyzed the data, contributed reagents/materials/analysis tools, wrote the paper, prepared figures and/or tables, and reviewed drafts of the paper.

\section{Figure Captions:}

Figure 1. Three frequently reoccurring phylogenetic hypotheses of the relationship between Balaenopteridae and Eschrichtiidae, as well as the relative placement of $N$. miocaena. Crown symbol designates crown Balaenopteroidea. A) The traditional view of monophyloetic Eschrichtiidae and Balaenopteridae (the latter including clades Balaenoptera and Megaptera). These relationships represent the historical view from the $20^{\text {th }}$ century (e.g., Rice 1998) as well as the results of most phylogenetic analyses based on morphological data (Marx 2011;

Bosselaers \& Post 2010; Boessenecker \& Fordyce 2015). B) The hypothesized phylogenetic relationships supported by analyses of molecular (McGowen et al. 2009; Sasaki et al. 2006) as well as combined molecular+morphological data (Marx \& Fordyce 2015; Slater et al. 2017). The latter studies including fossil and extant taxa as well from putative extinct members of Balaenopteridae and Eschrichtiidae sensu lato (Marx \& Kohno 2016; Slater et al. 2017). 
802 C) A third alternative hypothesis of large whale relationships resulting from molecular or

803 combined molecular+morphological data that recovers a monophyletic Balaenopteridae, but does

804 not recover a monophyletic genus Balaenoptera (Sasaki et al. 2006; Deméré et al. 2008; Gatesy

805 et al. 2013). In this scenario, Eschrichtiidae and Balaenopteridae are sister clades with

806 Megaptera nested within Balaenoptera and sister to B. physalus. Note the uncertainty regarding

807 the placement of N. miocaena inside the balaenopterids, inside the clade Megaptera, and outside

808 crown Balaenopteroidea (see text for further description of the data types and taxon sampling

809 that support these hypotheses).

810

811 Figure 2. Holotype skull (USNM 10300) of Norrisanima miocaena in dorsal view. A. Dorsal

812 view taken from 3D model created by laser scanning. B. Illustrated with a low opacity mask and

813 interpretive line art. Cross-hatching is matrix or plaster. Dotted lines indicate broken or missing

814 fragments. To view the 3D model of the specimen, visit the Smithsonian X 3D website at

815 (http://3d.si.edu).

816

817 Figure 3. Holotype skull (USNM 10300) of Norrisanima miocaena in ventral view. A.

818 Ventral view taken from 3D model created by laser scanning. B. Illustrated with a low opacity

819 mask and interpretive line art. Cross-hatching is matrix or plaster. Dotted lines indicate broken or 820 missing fragments. To view the 3D model of the specimen, visit the Smithsonian X 3D website 821 at (http://3d.si.edu).

822

823 Figure 4. Left temporal wall and orbital tegion of holotype skull (USNM 10300) of

824 Norrisanima miocaena. A. Anterodorsal; B. dorsolateral; C,D. dorsolateral enlarged. 
825

826 Figure 5. Right tympanic bulla of the holotype (USNM 10300) of Norrisanima miocaena.

827 Image taken from 3D model created by CT scanning and illustrated with a low opacity mask and

828 interpretive line art: A. dorsal, B. ventral, C. lateral, D. medial, E. anterior, F. posterior. Cross-

829 hatching is matrix or plaster. To view the 3D model of the specimen, visit the Smithsonian X 3D

830 website at (http://3d.si.edu).

831

832 Figure 6. Right periotic of the holotype (USNM 10300) of Norrisanima miocaena. Image

833 taken from 3D model created by CT scanning: A. dorsal, B. ventral, C. lateral, D. medial. To

834 view the 3D model of the specimen, visit the Smithsonian X 3D website at (http://3d.si.edu).

835

836 Figure 7. Comparisons of the vertex and dorsal surface of the cranium of Norrisamina

837 miocaena with some extant baleen whale species based on available 3D models. A. Caperea

838 marginata Gray 1846 (NHMUK 1876.2.16.1), B. Eubalaena australis (NHMUK 1873.3.3.1), C.

839 Balaenoptera edeni Anderson 1878 (NHMUK 1920.12.31.1), D. Megaptera novaeangliae

840 Borowski 1781 (NHMUK 792a), E. Norrisanima miocaena (USNM 10300), F. B. physalus

841 (NHMUK 1862.7.18.1), G. B. acutorostrata (NHMUK 1965.11.2.1), H. B. borealis (NHMUK

842 1934.5.25.1), I. B. musculus (NHMUK 1892.3.1.1). All NHMUK scans were downloaded from

843 https://doi.org/10.5519/0020467, with the exception of the blue whale which was acquired from

844 https://sketchfab.com/NHM_Imaging (Sabin et al 2018), and humpback whale, which was made

845 available directly from the NHMUK to the authors.

846 
847 Figure 8. Comparisons of the right periotic of Norrisamina miocaena with extant species

848 within Balaenoptera and Megaptera (except for C, all specimens are the right periotic; all

849 are shown in ventral view with the anterior oriented up). A. Balaenoptera bonaerensis

850 (USNM 504953), B. B. borealis (USNM 504699) C. B. physalus (USNM 237566), D.

851 Norrisanima miocaena (USNM 10300), E. Megaptera novaeangliae (USNM 486175). N.

852 miocaena is enlarged with a scale bar at $1 \mathrm{~cm}$; the scale bar for other periotics is $10 \mathrm{~cm}$. Numbered 853 characters are listed in Table 1: 1) Aperture of cranial nerve $(\mathrm{CN})$ ducts deeply recessed in pars 854 cochlearis (PC), 2) Aperture of CN ducts erupt medial; not deflected dorsally, 3) Dorsoventrally 855 flat and mediolaterally elongate PC, 4) Short and robust anterior process (AP) relative to size of 856 PC, 5) Presence of lateral crest on the ventral surface of AP, 6) Sharply pointed triangular flange, 857 7) Posteriorly deflected triangular flange, 8) Concave medial margin of PC, 9) Transverse ridge 858 on ventral surface of PC, 10) Deep invagination of fenestra ovalis.

859

860 Figure S1. Holotype skull (USNM 10300) of Norrisanima miocaena. Shown in A,B. Posterior; 861 and C,D. Lateral views.

862

863 Figure S2. Holotype skull (USNM 10300) of Norrisanima miocaena. Shown in A,B. Dorsal; 864 and C,D. Anterodorsal views.

865

866 Figure S3. Holotype periotics (USNM 10300) of Norrisanima miocaena. Left periotic shown

867 in A. Dorsal, B. Ventral, C. Medial, and D. Lateral views. Right periotic shown in E. Dorsal, F. 868 Ventral, G. Medial, and H. Lateral views. 
870 Figure S4. Holotype tympanic bullae (USNM 10300) of Norrisanima miocaena. Left periotic

871 shown in A. Ventral, B. Dorsal, C. Lateral, and D. Medial views. Right periotic shown in E.

872 Ventral, F. Dorsal, G. Lateral, and H. Medial views.

873

874 Figure S5. Holotype vertebra (USNM 10300) of Norrisanima miocaena. Shown in A.

875 Anterior, B. Dorsal, and C. Lateral views.

876

877 Figure S6. Holotype isolated portion of the vomer (USNM 10300) of Norrisanima miocaena.

878

879 
880 References:

881 Akiba F. 1986. Taxonomy, morphology and phylogeny of the Neogene diatom zonal marker 882 species in the middle-to-high latitudes of the North Pacific. Deep Sea Drilling Project

883 Initial Reports 87:483-554.

884

885

886

887

888

889

890

891

892

893

894

895

896

897

898

899

Anderson J. 1878. Balaenoptera. Cetacea. Anatomical and zoological researches: comprising an account of the zoological results of the two expeditions to western Yunnan in 1868 and 1875; and a monograph of the two cetacean genera, Platanista and Orcella. London: Bernard Quaritch, pp. 551-564.

Árnason Ú, Lammers F, Kumar V, Nilsson MA. and Janke, A., 2018. Whole-genome sequencing of the blue whale and other rorquals finds signatures for introgressive gene flow. Science Advances 4(4), p.eaap9873. DOI: 10.1126/sciadv.aap9873.

Barron JA, 1986. Paleoceanographic and tectonic controls on deposition of the Monterey Formation and related siliceous rocks in California. Palaeogeography, Palaeoclimatology, Palaeoecology 53(1), pp.27-45.

Barron JA, and Isaacs CM. 2001. Updated chronostratigraphic framework for the California Miocene. In Isaacs CM, and Ruellkötter J, eds., The Monterey Formation: From rocks to molecules: New York, Columbia University Press: 393-394.

Barron JA, Lyle M, and Koizumi I. 2001. Late Miocene and early Pliocene biosiliceous sedimentation along the California margin. Revista Mexicana de Ciencias Geológicas 19(3):161-169. DOI: 
900 Behl, R.J., and Ramirez, P.C., 2000. Field Guide to the Geology of the Neogene Santa Maria 901 Basin: From Rift to Uplift. In R.J. Behl (Ed) Field Guide to the Geology of the Neogene 902 903 Santa Maria Basin: From Rift to Uplift, Special Publication Pacific Section SEPM (Society for Sedimentary Geology), 86: 1-31

904 Bisconti M. 2007a. A new balaenopterid whale from the Pliocene of northern Italy. 905 Paleontology 50(5):1103-1122. 10.1111/j.1475-4983.2007.00696.x.

906

907

908

909

910

911

912

913

914

915

916

917

918

919

920
Bisconti M. 2007b. Taxonomic revision and phylogenetic relationships of the rorqual-like mysticete from the Pliocene of Mount Pulgnasco, northern Italy (Mammalia, Cetacea, Mysticeti). Paleontographica Italica 91:85-108. DOI: 10.1080/02724631003762922.

Bisconti M. 2010a. A new balaenopterid whale from the Late Miocene of the Stirone River, northern Italy (Mammalia, Cetacea, Mysticeti). Journal of Vertebrate Paleontology 30:943-958. DOI: 10.1080/02724631003762922.

Bisconti M. 2010b. New description of "Megaptera" hubachi Dathe, 1983, based on the holotype skeleton held in the Museum für Naturkunde, Berlin. 2010. Quaderni del Museo di Storia Naturale di Livorno 23:37-68. DOI: 10.4457/musmed.2010.23.37.

Bisconti M, Munsterman DK, Post K. 2019. A new balaenopterid whale from the late Miocene of the Southern North Sea Basin and the evolution of balaenopterid diversity (Cetacea, Mysticeti). PeerJ 7:e6915

Boessenecker RW. 2012. A new marine vertebrate assemblage from the Late Neogene Purisima Formation in Central California, part II: Pinnipeds and Cetaceans. Geodiversitas, 35(4):815-940. DOI: 10.5252/g2013n4a5

Peer) reviewing PDF | (2018:07:29605:2:2:NEW 26 Jul 2019) 
921 Boessenecker RW, and Fordyce RE. 2015. Anatomy, feeding ecology, and ontogeny of a

922 transitional baleen whale: a new genus and species of Eomysticetidae (Mammalia:

923 Cetacea) from the Oligocene of New Zealand. PeerJ 3: e1129. DOI: 10.7717/peerj.1129.

924 Boessenecker RW, and Fordyce RE. 2017. A new eomysticetid from the Oligocene Kokoamu 925 Greensand of New Zealand and a review of the Eomysticetidae (Mammalia, Cetacea).

926

927 Journal of Systematic Palaeontology, 15(6):429-469. DOI:

10.1080/14772019.2016.1191045.

928

929

930

931

932

933

934

935

936

937

938

939

Borowski GH. 1781. Gemeinnüzzige Naturgeschichte des Thierreichs: darinn die merkwürdigsten und nüzlichsten Thiere in systematischer Ordnung beschrieben und alle Geschlechter in Abbildungen nach der Natur vorgestellet warden. Berlin 2(1).

Bosselaers M, and Post K, 2010. A new fossil rorqual (Mammalia, Cetacea, Balaenopteridae) from the Early Pliocene of the North Sea, with a review of the rorqual species described by Owen and Van Beneden. Geodiversitas 32(2):331-363. DOI: 10.5252/g2010n2a6.

Brisson MJ. 1762. Regnum animale in Classes IX distributum, sive synopsis methodica sistens generalem animalium distributionem in Classes IX, et duarum primarum Classium, Quadrupedum scilicet \& Cetaceorum, particulare divisionem in Ordines, Sectiones, Genera, et Species. Paris: T. Haak.

Burmeister H. 1868. Preliminary description of a new species of finner whale (Balaenoptera bonaerensis). Proceedings of the Zoological Society of London 1867: 707-713. 
940 Cantino PD, \& De Queiroz K. 2014. PhyloCode: a phylogenetic code of biological

941 nomenclature. (Version 4c). Ohio University. Available at

942 http://www.ohiou.edu/phylocode

943 Chang AS, and Grimm KA. 1999. Speckled beds: distinctive gravity-flow deposits in finely

944 laminated diatomaceous sediments, Miocene Monterey Formation, California. Journal of

945 Sedimentary Research 69. DOI: 10.2110/jsr.69.122.

946 Cignoni P, Callieri M, Corsini M, Dellepiane M, Ganovelli F, and Ranzuglia G. 2008. Meshlab:

947

948 an open-source mesh processing tool. Eurographics Italian Chapter Conference. 129-136. DOI: 10.2312/LocalChapterEvents/ItalChap/ItalianChapConf2008/129-136

Dathe F. 1983. Megaptera hubachi n. sp., ein fossiler Bartenwal aus marinen Sandsteinschichten 950 des tieferen Pliozäns Chiles. Zeitschrift für Geologische Wissenschaften 11: 813-852.

951

952

953

954

955

956

957

958

Deméré TA, Berta A, and McGowen MR. 2005. The taxonomic and evolutionary history of fossil and modern balaenopteroid mysticetes. Journal of Mammalian Evolution 12:99143. DOI:10.1007/s10914-005-6944-3.

Deméré TA, McGowen MR, Berta A, and Gatesy J. 2008. Morphological and molecular evidence for a stepwise evolutionary transition from teeth to baleen in mysticete whales. Systematic Biology, 57(1): 15-37. DOI: 10.1080/10635150701884632

Desmoulins A. 1822. Baleine. Balaena. Mam. In: Dictionnaire Classique d'Histoire naturelle. 2: 155-165. Paris: Rey et Gravier. 
959 Dibblee TW Jr. 1950. Geology of southwestern Santa Barbara County, California. California $960 \quad$ Division of Mines Bulletin 105: 1-95.

961 Ekdale EG, Berta A, and Deméré TA. 2011. The comparative osteology of the petrotympanic 962 complex (ear region) of extant baleen whales (Cetacea: Mysticeti). PLoS ONE 6:e21311. 963 DOI: 10.1371/journal.pone.0021311.

964 Fordyce RE, de Muizon C. 2001. Evolutionary history of whales: a review. In: Mazin JM, De 965 Buffrenil V, eds. Secondary adaptation of tetrapods to life in water. München: Pfeil. 169$966 \quad 234$

967 Gatesy J, Geisler JH, Chang J, Buell C, Berta A, Meredith RW, Springer MS, and McGowen 968 MR. 2013. A phylogenetic blueprint for a modern whale. Molecular Phylogenetics and 969 Evolution 66:479-506. DOI: 10.1016/j.ympev.2012.10.012.

970 Geisler JH, McGowen MR, Yang G, Gatesy J. 2011. A supermatrix analysis of genomic, 971 morphological, and paleontological data from crown Cetacea. BMC Evolutionary

972 Biology 11(1), p.112.

973 Geisler JH, Boessenecker RW, Brown M, and Beatty BL. 2017. The origin of filter feeding in 974 whales. Current Biology 27(13):2036-2042. DOI: 10.1016/j.cub.2017.06.003

975

976

977
Geisler JH, McGowen MR, Yang G, Gatesy J. 2011. A supermatix analysis of genomic, morphological, and paleontological data from crown Cetacea. BMC Evolutionary Biology 11:112. DOI:10.1186/1471-2148-11-112 
978 Gray JE. 1846. On the cetaceous animals. The zoology of the voyage of H. M. S. Erebus and

979 Terror, under the command of Capt. Sir J. C. Ross, R. N., F. R. S., during the years 1839

$980 \quad$ to $18431 \& 2: 1-53$.

981 Gray JE. 1864. On the Cetacea which have been observed in the seas surrounding the British

982 Islands. Proceedings of the Scientific Meetings of the Zoological Society of London

983 1864:195-248.

984

Gray JE. 1868. Synopsis of the species of whales and dolphins in the collection of the British 985 Museum. Bernard Quaritch: 1-10.

Hanna GD, and McLellan ME. 1924. A new species of fin whale from the type locality of the 987 Monterey Group. Proceedings of the California Academy of Sciences 13: 237-241.

Joyce WG, Parham JF, \& Gauthier JA. 2004. Developing a protocol for the conversion of rankbased taxon names to phylogenetically defined clade names, as exemplified by turtles. Journal of Paleontology 78(5): 989-1013.

Kellogg R. 1922. Description of the skull of Megaptera miocaena, a fossil humpback whale from the Miocene diatomaceous earth of Lompoc, California. Proceedings of the United 993 States National Museum 61(14):1-18.

Kellogg R. 1925. New pinnipeds from the Miocene diatomaceous earth near Lompoc, California. Contributions to Palaeontology from the Carnegie Institution of Washington 348:71-95. United States National Museum 247(1):1-45. 
998 Kimura T, and Hasegawa Y. 2010. A new baleen whale (Mysticeti: Cetotheriidae) from the 999 earliest late Miocene of Japan and a reconsideration of the phylogeny of cetotheres. 1000 Journal of Vertebrate Paleontology 30(2): 577-591.

1001 Kleinpell RM. 1938. Miocene stratigraphy of California. American Association of Petroleum 1002 Geologists. Tulsa, Oklahoma. 450 p.

1003 Lacépède BGÉ. 1804. Histoire Naturelle des Cétacées, dediée à Anne-Caroline La Cepède: par le 1004 Citoyen La Cepède. Plassan, Paris. pp. 329.

1005 Lilljeborg W. 1861. Supplément au mémoire sur les genres Liriope et Peltogaster, H. Rathke. 1006 Nova Acta Regiae Societatis Scientiarum Upsaliensis, Seriei Tertiae 3:74-102.

1007 Lesson RP. 1828. Histoire Naturelle, Générale et Particulière des Mammifères et des Oiseaux 1008 Découverts depuis 1788 jusqu'à nos Jours. Complément des oeuvres de Buffon, ou 1009 historie naturelle des animaux rares découverts par les naturalistes et les voyageurs 1010 depuis la mort de Buffon. Tom. 1 Cétacés. Baudoin Frères, Paris. pp. 442.

1011 Linnaeus C. 1758. Systema naturae per regna tria naturae, secundum classes, ordines, genera, 1012 species, cum characteribus, differentiis, synonymis, locis. Tomus 1, Editio decima, 1013 reformata. Stockholm: Laurentii Salvii. 1-824.

1014 Marx FG. 2011. The more the merrier? A large cladistic analysis of mysticetes, and comments 1015 on the transition from teeth to baleen. Journal of Mammal Evolution 18: 77-100 DOI $1016 \quad 10.1007 / \mathrm{s} 10914-010-9148-4$. 
1017 Marx FG, and Fordyce RE. 2015. Baleen boom and bust: a synthesis of mysticete phylogeny, 1018 diversity and disparity. Royal Society Open Science 2(4): 140434. DOI:

$1019 \quad 10.1098 /$ rsos.140434.

1020 Marx FG, and Kohno N. 2016. A new Miocene baleen whale from the Peruvian desert. Royal $1021 \quad$ Society Open Science 3:160542. DOI: 10.1098/rsos.160542.

1022 McGowen MR, Spaulding M. and Gatesy J. 2009. Divergence date estimation and a 1023 comprehensive molecular tree of extant cetaceans. Molecular Phylogenetics and 1024 Evolution, 53(3): 891-906. DOI: 10.1016/j.ympev.2009.08.018.

1025 Mead JG, and Fordyce RE. 2009. The therian skull: a lexicon with emphasis on the odontocetes. 1026 Smithsonian Contributions to Zoology: 1-248. DOI: 10.5479/si.00810282.627.

Mitchell ED. 1968. The Mio-Pliocene pinniped Imagotaria. Journal of the Fisheries Research Board of Canada 25(9):1843-1900.

1029 Oishi M, and Hasegawa Y. 1994. A list of fossil cetaceans in Japan. Island Arc 3(4): 493-505.

1030 Omura H, Kasuya T, Kato H, Wada S. 1981. Osteological study of the Bryde's whale from the 1031 central south Pacific and eastern Indian Ocean. Scientific Report of the Whales Research Institute, 33: 1-26 Joyce WG, Ksepka DT, Patané JS, Smith ND, Tarver JE, van Tuinen M, Yang Z, Angielczyk KD, Greenwood JM, Hipsley CA, Jacobs L, Makovicky PJ, Müller J, Smith 
1036

1037

1038

1039

1040

1041

1042

1043

1044

1045

1046

1047

1048

1049

1050

1051

1052

1053

1054

1055

KT, Theodor JM, Warnock RCM, Benton MJ. 2012. Best practices for justifying fossil calibrations. Systematic Biology, 61(2):346-359. DOI: 10.1093/sysbio/syr107.

Pilleri G. 1989. Balaenoptera siberi, ein neuer spätmiozäner Bartenwal aus der Pisco-Formation Perus. Beiträge zur Paläontologie der Cetaceen Perus Hirnanatomisches Institut Ostermundingen, Bern: 63-84.

Pilleri G. 1990. Paratypus von Balaenoptera siberi (Cetacea: Mysticeti) aus der Pisco Formation Perus. Beiträge zur paläontologie der cetaceen und pinnipedier der Pisco Formation Perus II Waldau-Berne, Switzerland: Hirnanatomisches Istitut der Universitat Bern Ostermundigen (Schweiz): 205-215.

Pyenson ND, Vélez-Juarbe J, Gutstein CS, Little H, Vigil D, \& O'Dea A. 2015. Isthminia panamensis, a new fossil inioid (Mammalia, Cetacea) from the Chagres Formation of Panama and the evolution of 'river dolphins' in the Americas. PeerJ, 3, e1227. doi:10.7717/peerj.1227.

Pyenson ND, and Sponberg SN. 2011. Reconstructing body size in extinct crown Cetacea (Neoceti) using allometry, phylogenetic methods and tests from the fossil record Journal of Mammal Evolution 18(4): 269. DOI: 10.1007/s10914-011-9170-1.

Repenning CA, and Tedford RH. 1977. Otarioid seals of the Neogene. United States Geological Survey Professional Paper 992:1-93.

Rice DW. 1998. Marine mammals of the world, systematics and distribution. Society for Marine Mammology Special Publication 4:1-231. 
1056 Ronquist F, Teslenko M, Van Der Mark P, Ayres DL, Darling A, Höhna S, Larget B, Liu L, 1057 Suchard MA, and Huelsenbeck JP. 2012. MrBayes 3.2: efficient Bayesian phylogenetic

1058

1059 inference and model choice across a large model space. Systematic Biology 61(3): 539542.

1060 Sabin R, Burton K, Cooper N, Goswami A. 2018. Dataset: 3D Cetacean Scanning. Natural

1061 History Museum Data Portal (data.nhm.ac.uk). DOI: https://doi.org/10.5519/0020467

1062 Sasaki, T., Masato N, Wada S, Yamada TK, Cao Y, Hasegawa M, Okada N. 2006. Balaenoptera

1063 omurai is a newly discovered baleen whale that represents an ancient evolutionary

1064 lineage. Molecular Phylogenetetics and Evolution 41(1): 40-52. DOI:

1065 10.1016/j.ympev.2006.03.032

1066

1067

1068

1069

1070

1071

1072

1073

1074

1075

1076
Slater GJ, Goldbogen JA, and Pyenson ND. 2017. Independent evolution of baleen whale gigantism linked to Plio-Pleistocene ocean dynamics. Proceedings of the Royal Society B: Biological Sciences 284. DOI: 10.1098/rspb.2017.0546

Uhen MD. 2008. New protocetid whales from Alabama and Mississippi, and a new cetacean clade, Pelagiceti. Journal of Vertebrate Paleontology 28(3):589-593

Velez-Juarbe J. 2017. Eotaria citrica, sp. nov., a new stem otariid from the "Topanga" formation of Southern California. PeerJ 5:e3022

Zeigler CV, Chan GL, and Barnes LG. 1997. A new Late Miocene balaenopterid whale (Cetacea Mysticeti), Parabalaenoptera baulinensis (new genus and species) from the Santa Cruz Mudstone, Point Reyes Peninsula, California. Proceedings of the California Academy of Sciences 50:115-138. 


\section{Table $\mathbf{1}$ (on next page)}

Ten characters of the periotic that broadly distinguish Balaenoptera and Megaptera, and how Norrisanima compares to these genera $(\mathrm{Y} / \mathrm{N})$.

Column abbreviations: $\mathrm{B}=$ Balaenoptera; $\mathrm{M}=$ Megaptera, $\mathrm{N}=$ Norrisanima . Character abbreviations: $\mathrm{PC}=$ pars cochlearis; $\mathrm{CN}=$ cranial nerves; $\mathrm{AP}=$ anterior process. View abbreviations: $\mathrm{M}=$ medial, $\mathrm{D}=$ dorsal, $\mathrm{V}=$ ventral. 
1

\begin{tabular}{rlcccc}
\hline \# & Character & $\boldsymbol{B}$ & $\boldsymbol{M}$ & $\boldsymbol{N}$ & View \\
\hline $\mathbf{1}$ & Aperture of CN ducts deeply recessed in PC & $\mathrm{N}$ & $\mathrm{Y}$ & $\mathrm{Y}$ & $\mathrm{M}, \mathrm{D}$ \\
$\mathbf{2}$ & Aperture of CN ducts erupt medial; not deflected dorsally & $\mathrm{N}$ & $\mathrm{Y}$ & $\mathrm{Y}$ & $\mathrm{M}, \mathrm{D}$ \\
$\mathbf{3}$ & Dorsoventrally flat and mediolaterally elongate PC & $\mathrm{N}$ & $\mathrm{Y}$ & $\mathrm{Y}$ & $\mathrm{V}$ \\
$\mathbf{4}$ & Short and robust AP relative to size of PC & $\mathrm{N}$ & $\mathrm{Y}$ & $\mathrm{Y}$ & $\mathrm{V}, \mathrm{D}$ \\
$\mathbf{5}$ & Presence of lateral crest on the ventral surface of AP & $\mathrm{N}$ & $\mathrm{Y}$ & $\mathrm{N}$ & $\mathrm{V}$ \\
$\mathbf{6}$ & Sharply pointed triangular flange & $\mathrm{N}$ & $\mathrm{Y}$ & $\mathrm{N}$ & $\mathrm{V}, \mathrm{D}$ \\
$\mathbf{7}$ & Posteriorly deflecting triangular flange & $\mathrm{N}$ & $\mathrm{Y}$ & $\mathrm{N}$ & $\mathrm{V}, \mathrm{D}$ \\
$\mathbf{8}$ & Concave medial margin of PC & $\mathrm{N}$ & $\mathrm{Y}$ & $\mathrm{Y}$ & $\mathrm{V}, \mathrm{D}$ \\
$\mathbf{9}$ & Transverse ridge on ventral surface of PC & $\mathrm{N}$ & $\mathrm{Y}$ & $\mathrm{N}$ & $\mathrm{V}$ \\
$\mathbf{1 0}$ & Deep invagination of fenestra ovalis & $\mathrm{N}$ & $\mathrm{Y}$ & $\mathrm{Y}$ & $\mathrm{V}$ \\
\hline
\end{tabular}

2

3 


\section{Figure 1}

Three frequently reoccurring phylogenetic hypotheses of the relationship between Balaenopteridae and Eschrichtiidae, as well as the relative placement of $N$. miocaena.

Crown symbol designates crown Balaenopteroidea. A) The traditional view of monophyloetic Eschrichtiidae and Balaenopteridae (the latter including clades Balaenoptera and Megaptera). These relationships represent the historical view from the $20^{\text {th }}$ century (e.g., Rice 1998) as well as the results of most phylogenetic analyses based on morphological data (Marx 2011; Bosselaers \& Post 2010; Boessenecker \& Fordyce 2015). B) The hypothesized phylogenetic relationships supported by analyses of molecular (McGowen et al. 2009; Sasaki et al. 2006) as well as combined molecular+morphological data (Marx \& Fordyce 2015; Slater et al. 2017). The latter studies including fossil and extant taxa as well from putative extinct members of Balaenopteridae and Eschrichtiidae sensu lato (Marx \& Kohno 2016; Slater et al. 2017). C) A third alternative hypothesis of large whale relationships resulting from molecular or combined molecular+morphological data that recovers a monophyletic Balaenopteridae, but does not recover a monophyletic genus Balaenoptera (Sasaki et al. 2006; Deméré et al. 2008; Gatesy et al. 2013). In this scenario, Eschrichtiidae and Balaenopteridae are sister clades with Megaptera nested within Balaenoptera and sister to B. physalus. Note the uncertainty regarding the placement of $N$. miocaena inside the balaenopterids, inside the clade Megaptera, and outside crown Balaenopteroidea (see text for further description of the data types and taxon sampling that support these hypotheses). 
A.

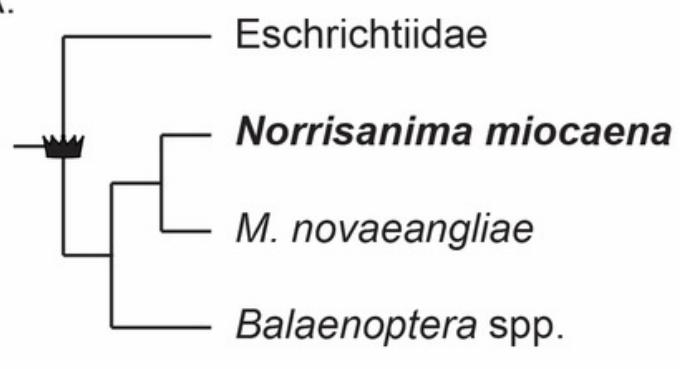

B.

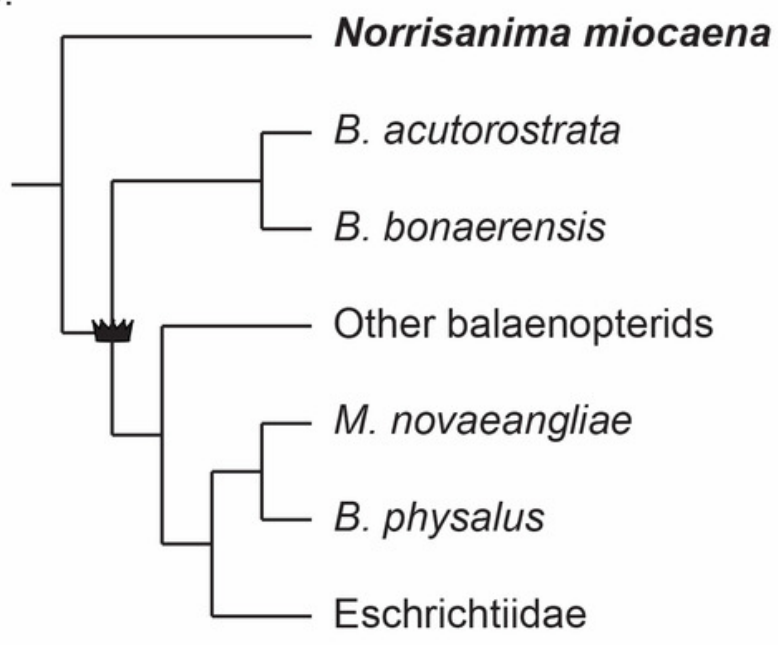

C.

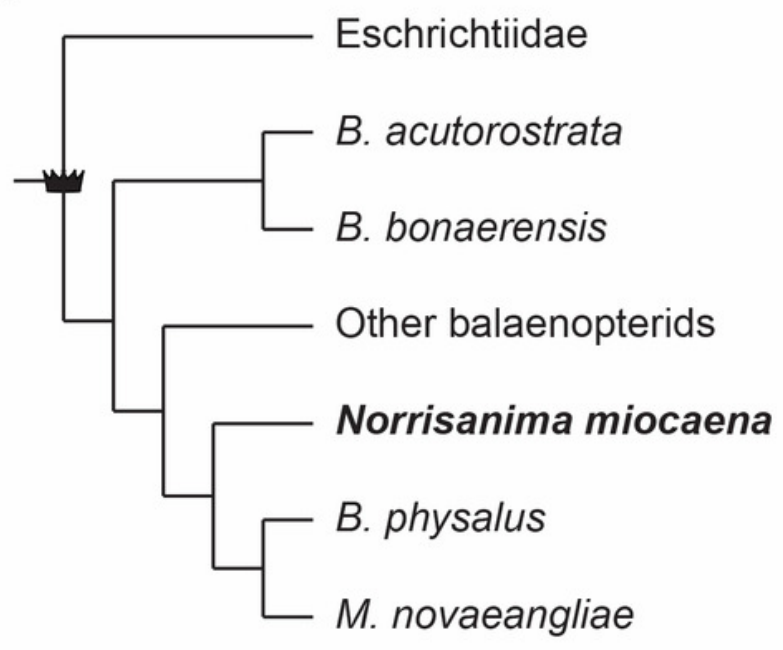


Figure 2

Holotype skull (USNM 10300) of Norrisanima miocaena in dorsal view.

Dorsal view taken from 3D model created by laser scanning. B. Illustrated with a low opacity mask and interpretive line art. Cross-hatching is matrix or plaster. Dotted lines indicate broken or missing fragments. To view the 3D model of the specimen, visit the Smithsonian $X$ 3D website at ( http://3d.si.edu ). 
A.

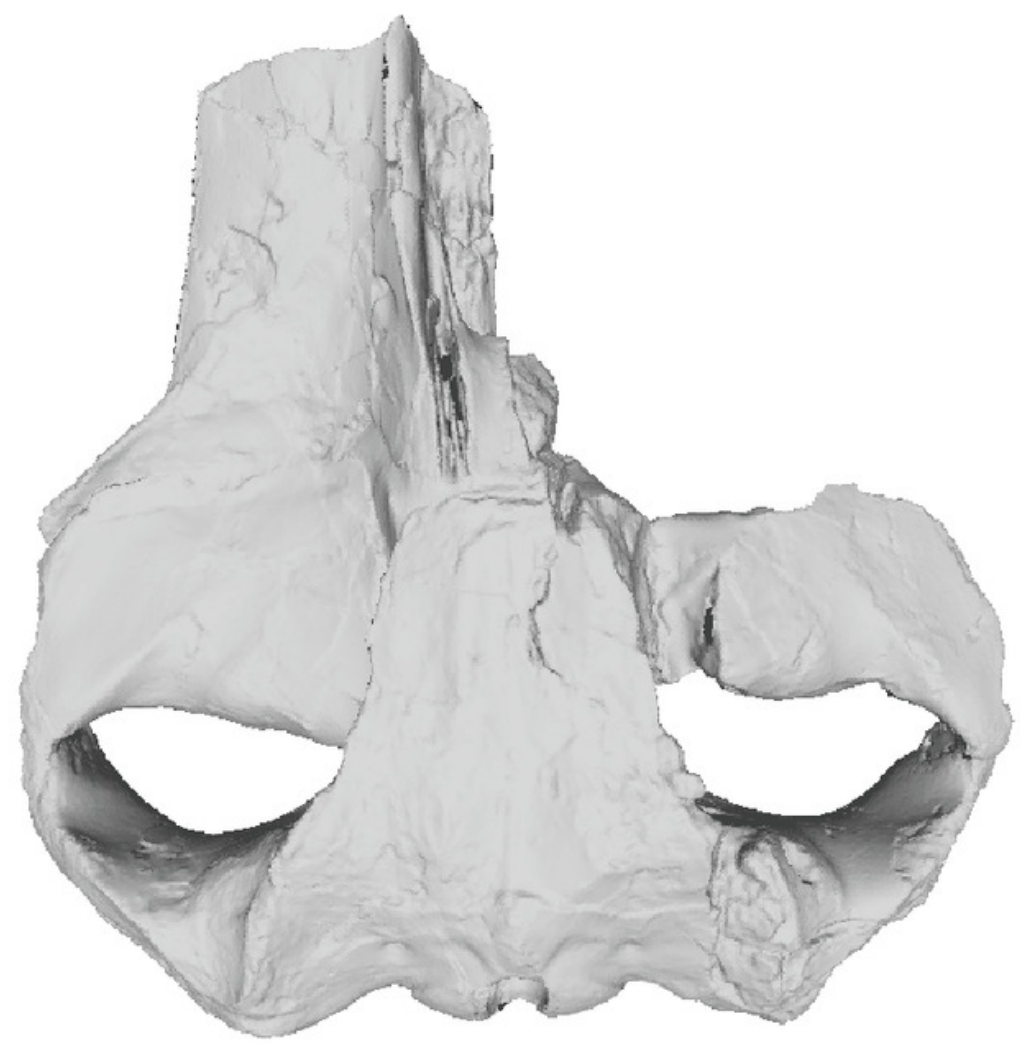

B.

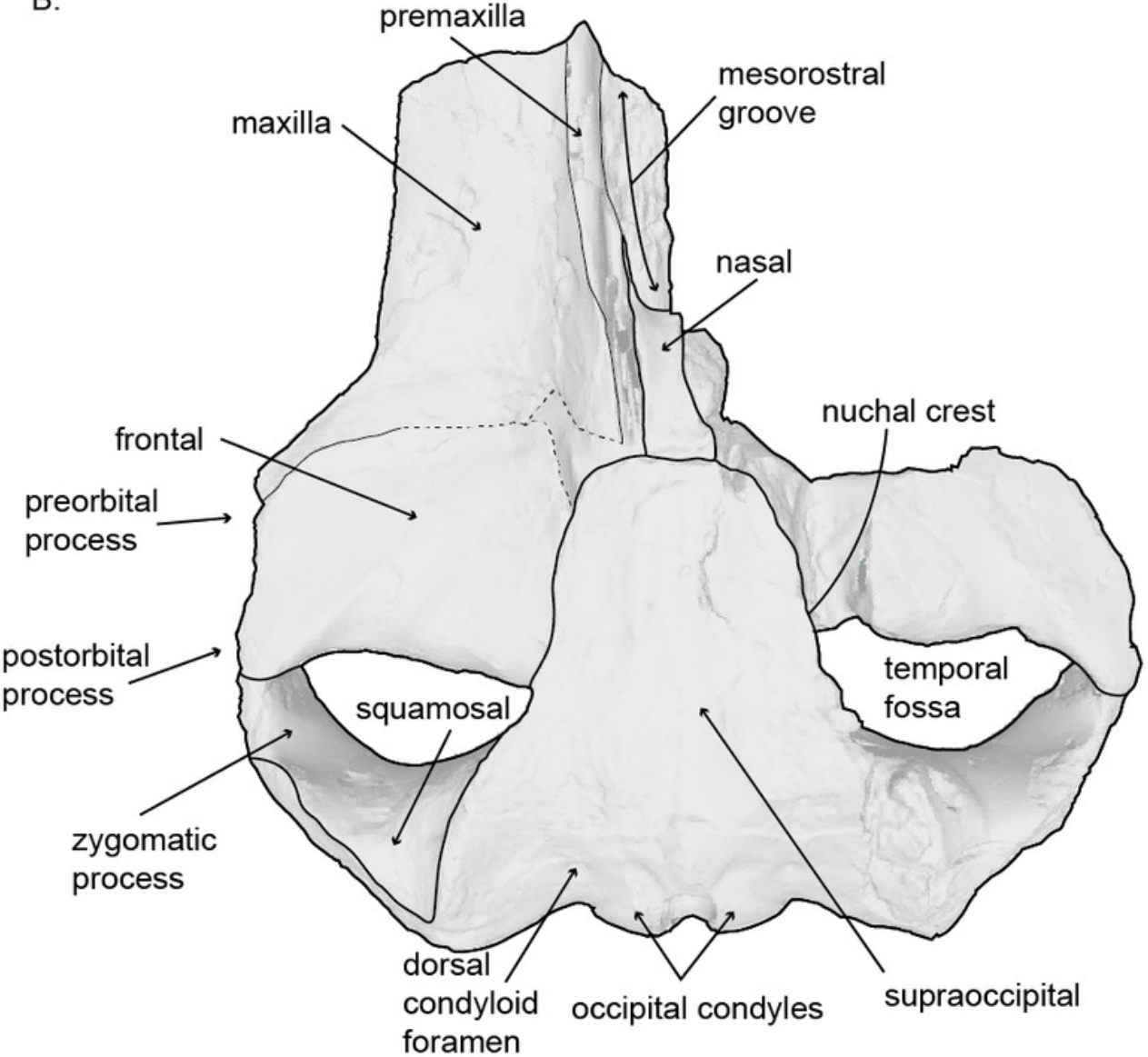




\section{Figure 3}

Holotype skull (USNM 10300) of Norrisanima miocaena in ventral view.

Ventral view taken from 3D model created by laser scanning. B. Illustrated with a low opacity mask and interpretive line art. Cross-hatching is matrix or plaster. Dotted lines indicate broken or missing fragments. To view the 3D model of the specimen, visit the Smithsonian $X$ 3D website at ( http://3d.si.edu ). 
A.

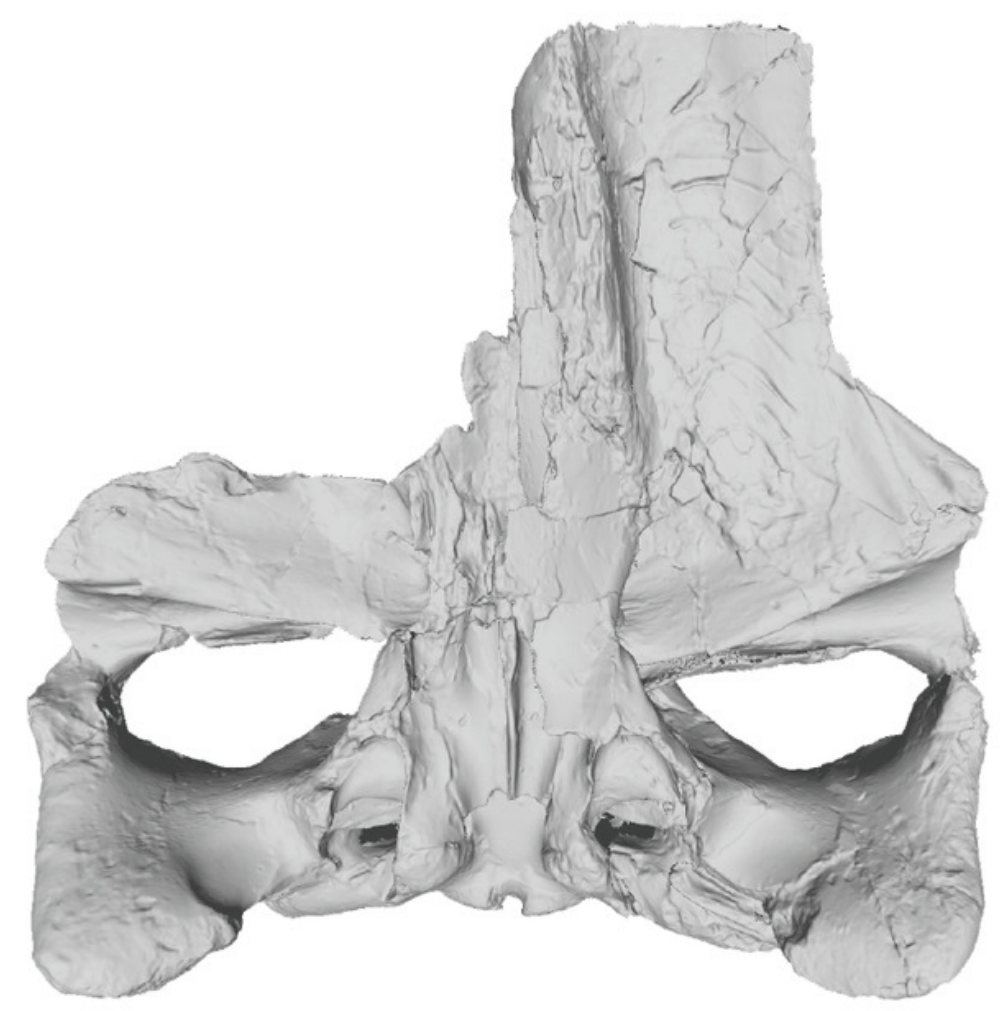

B.

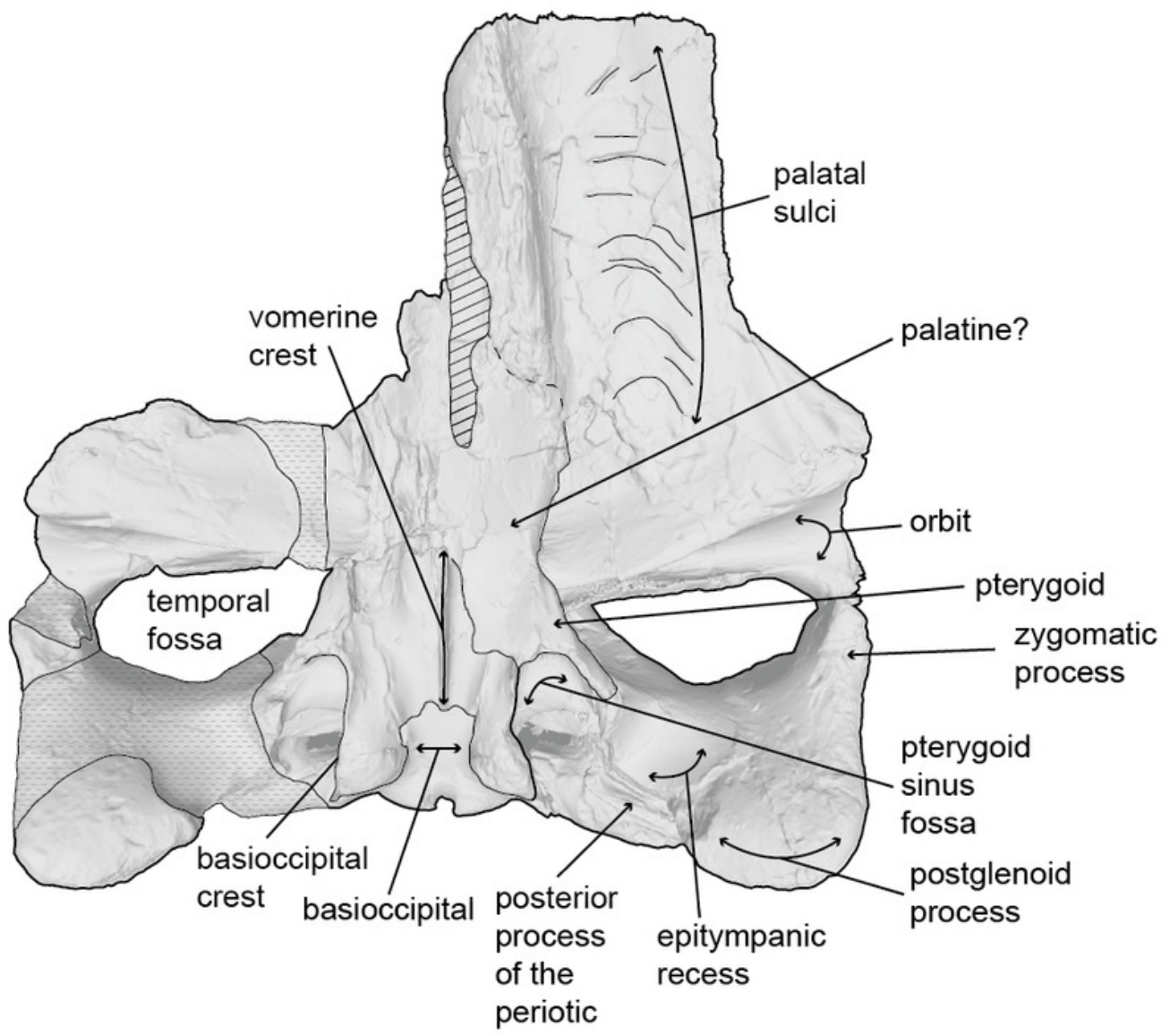


Figure 4

Left temporal wall and orbital tegion of holotype skull (USNM 10300) of Norrisanima miocaena.

A. Anterodorsal; B. dorsolateral; C,D. dorsolateral enlarged.

A.

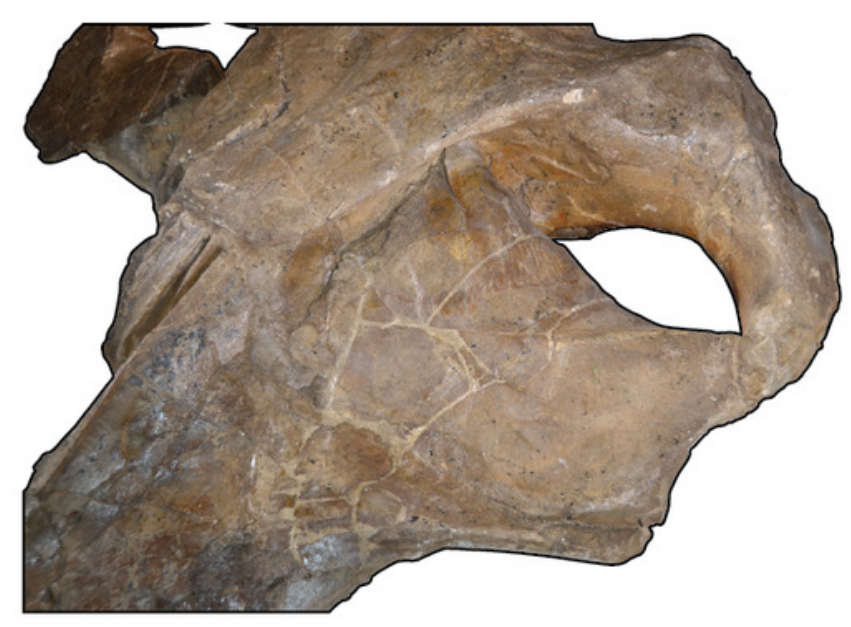

C.

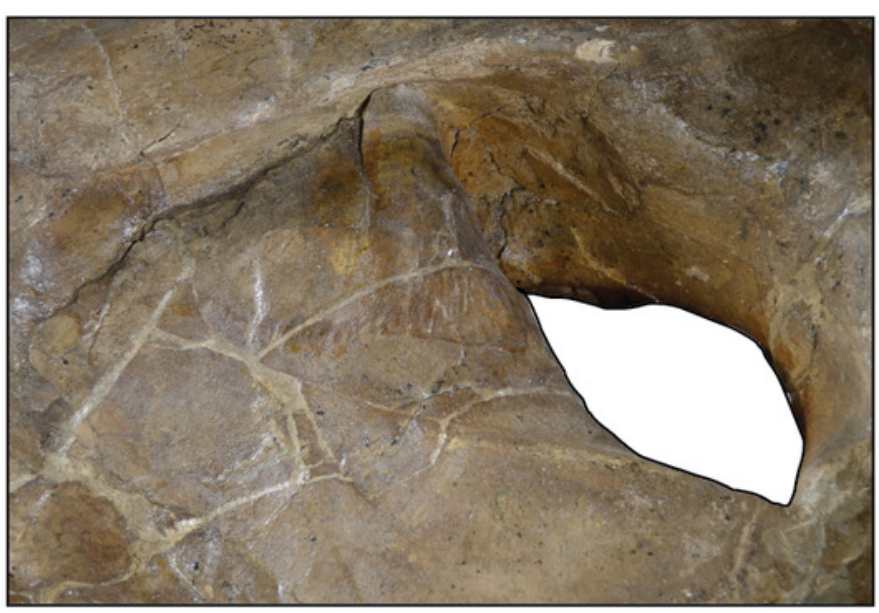

B.

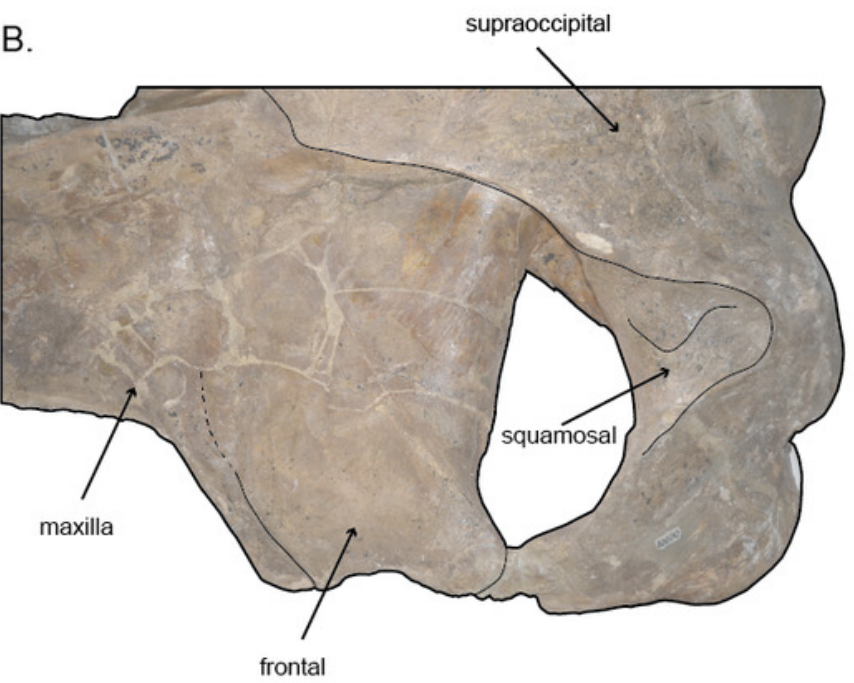

D.

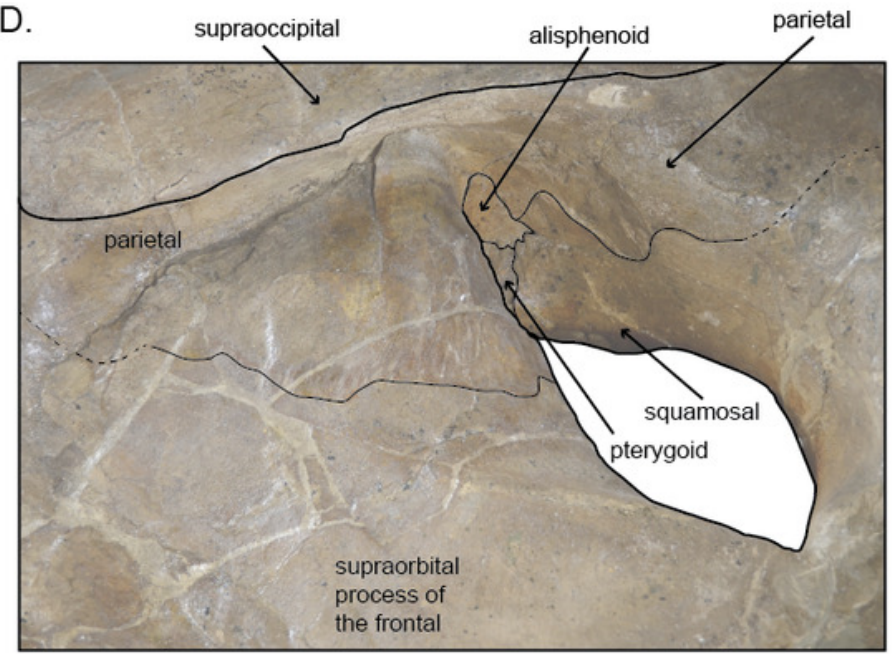




\section{Figure 5}

Right tympanic bulla of the holotype (USNM 10300) of Norrisanima miocaena.

Image taken from 3D model created by CT scanning and illustrated with a low opacity mask and interpretive line art: A. dorsal, B. ventral, C. lateral, D. medial, E. anterior, F. posterior. Cross-hatching is matrix or plaster. To view the 3D model of the specimen, visit the Smithsonian X 3D website at ( http://3d.si.edu ). 
A.

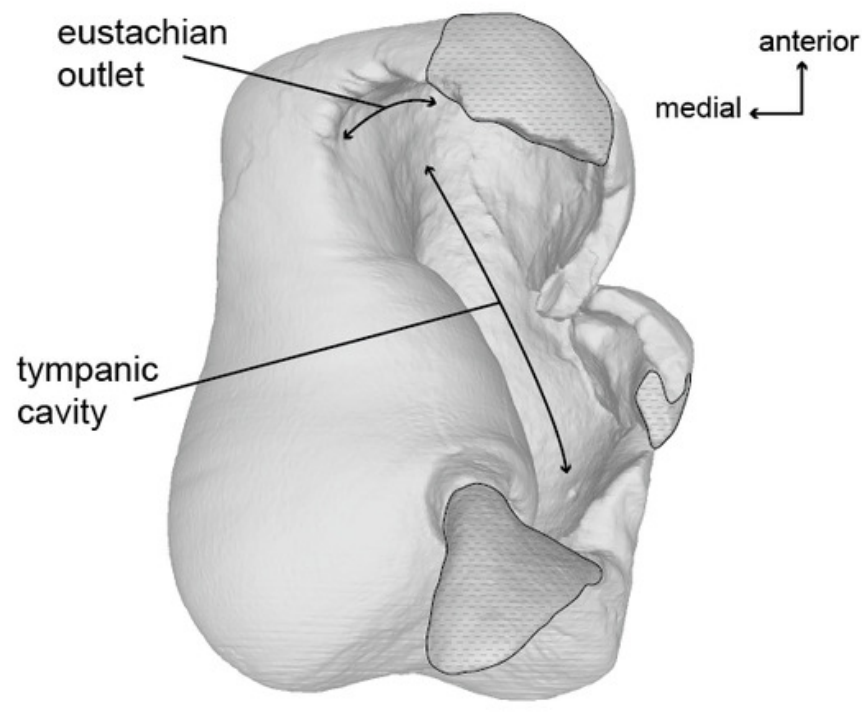

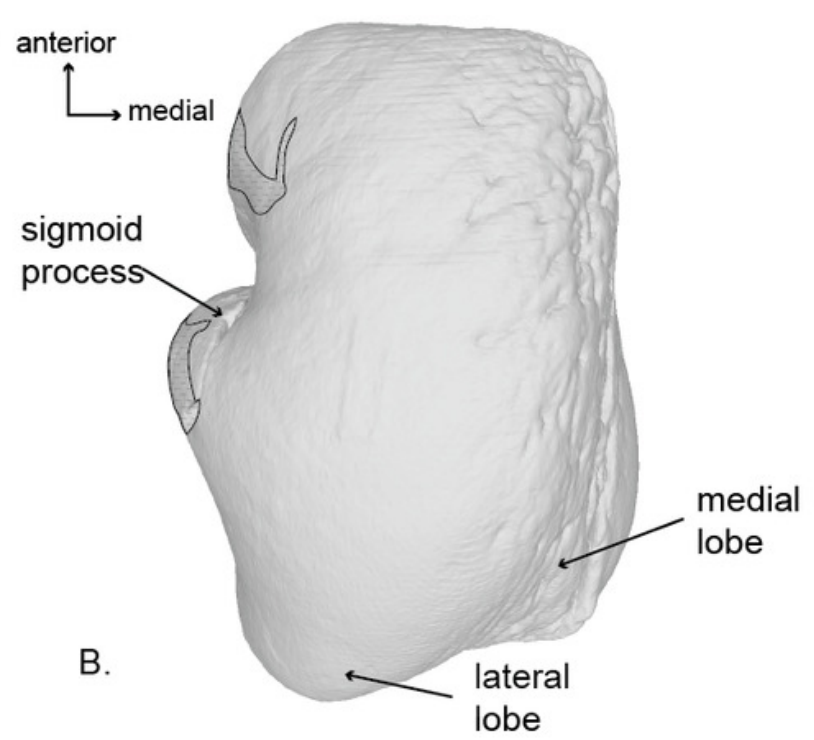

C.

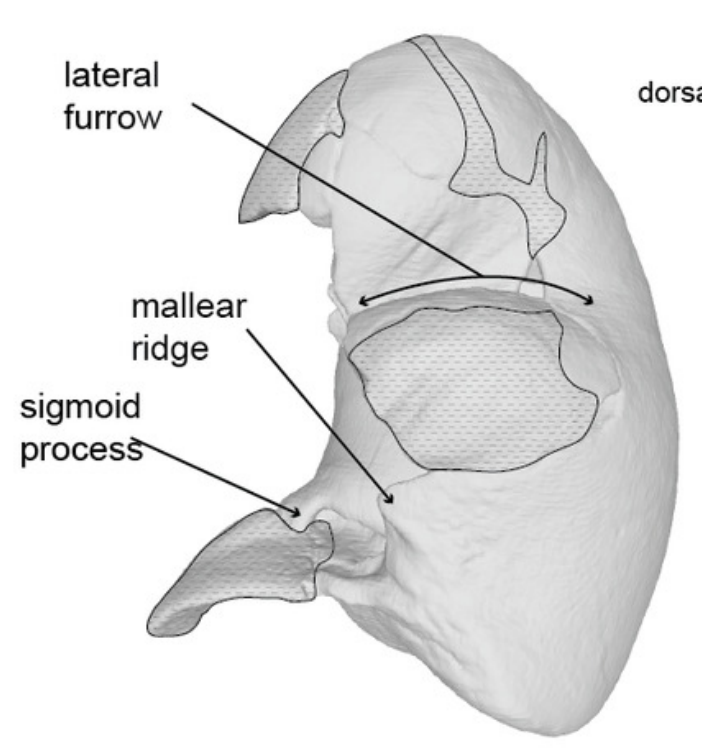

anterior anterior
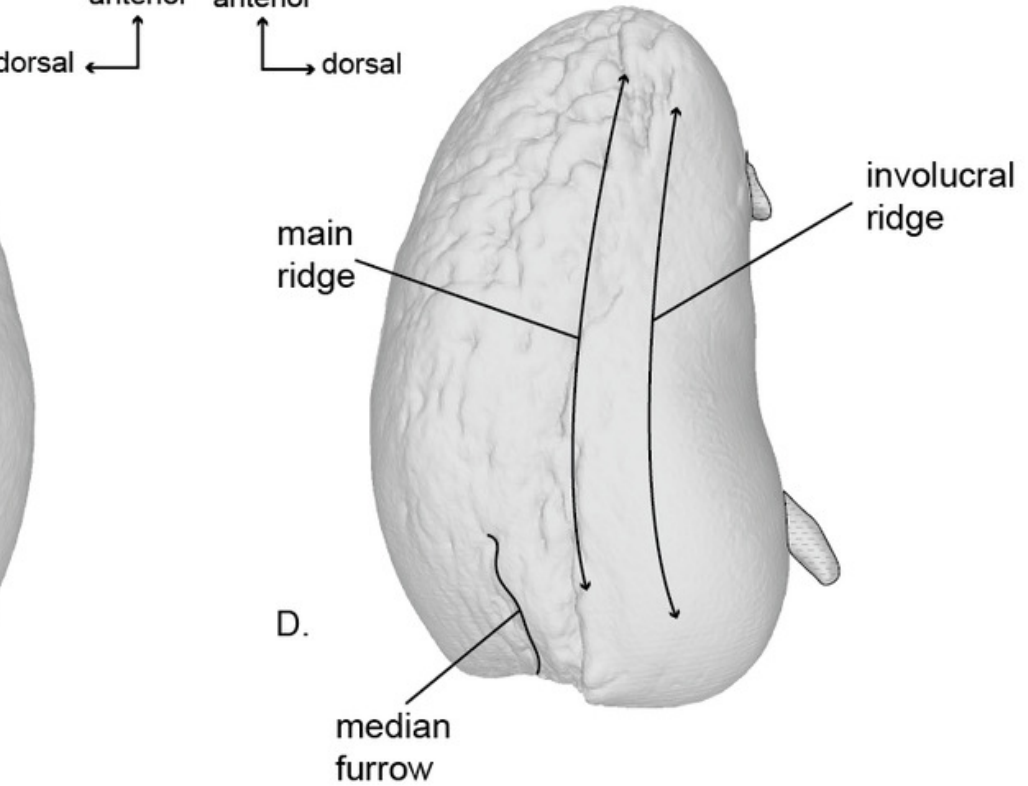

E.

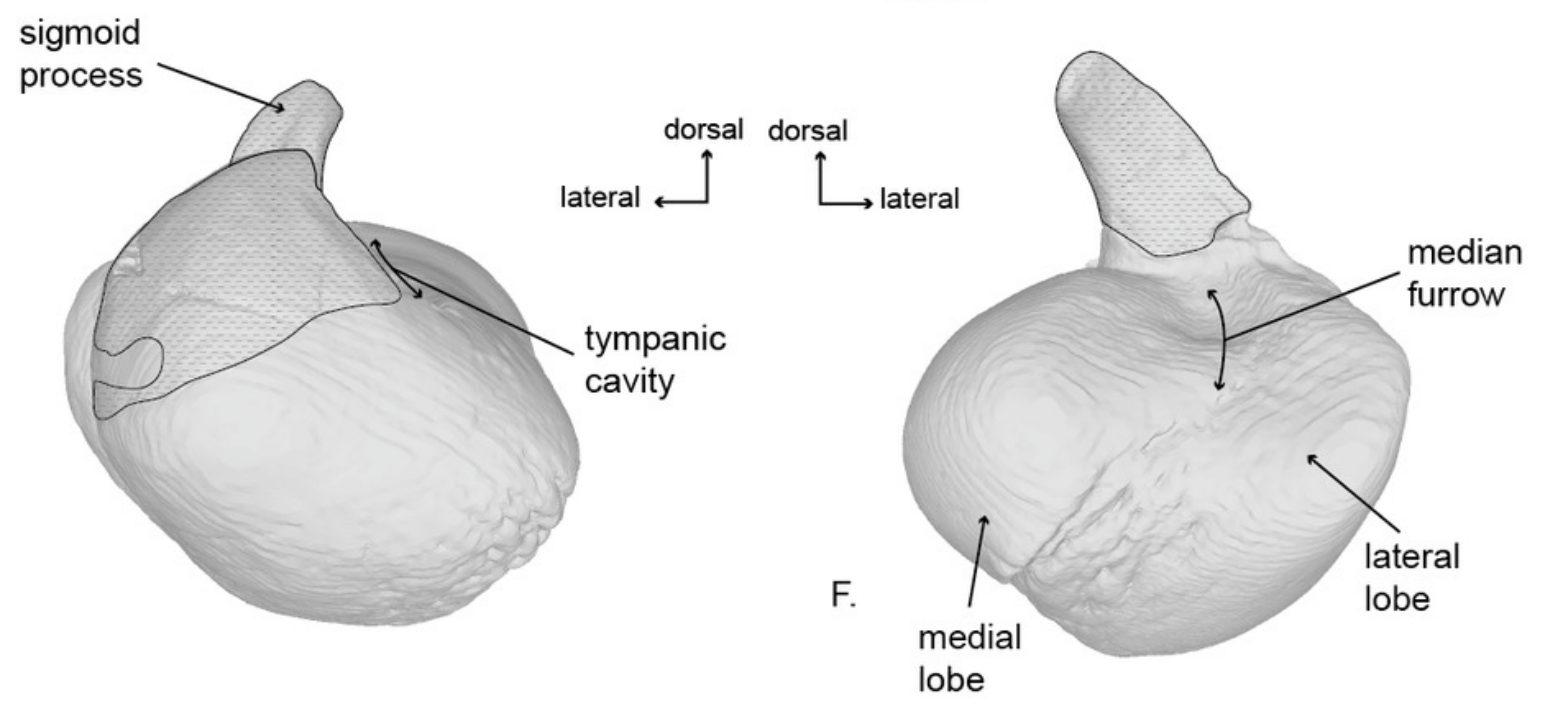


Figure 6

Right periotic of the holotype (USNM 10300) of Norrisanima miocaena.

Image taken from 3D model created by CT scanning: A. dorsal, B. ventral, C. lateral, D. medial. To view the 3D model of the specimen, visit the Smithsonian X 3D website at ( http://3d.si.edu ). 

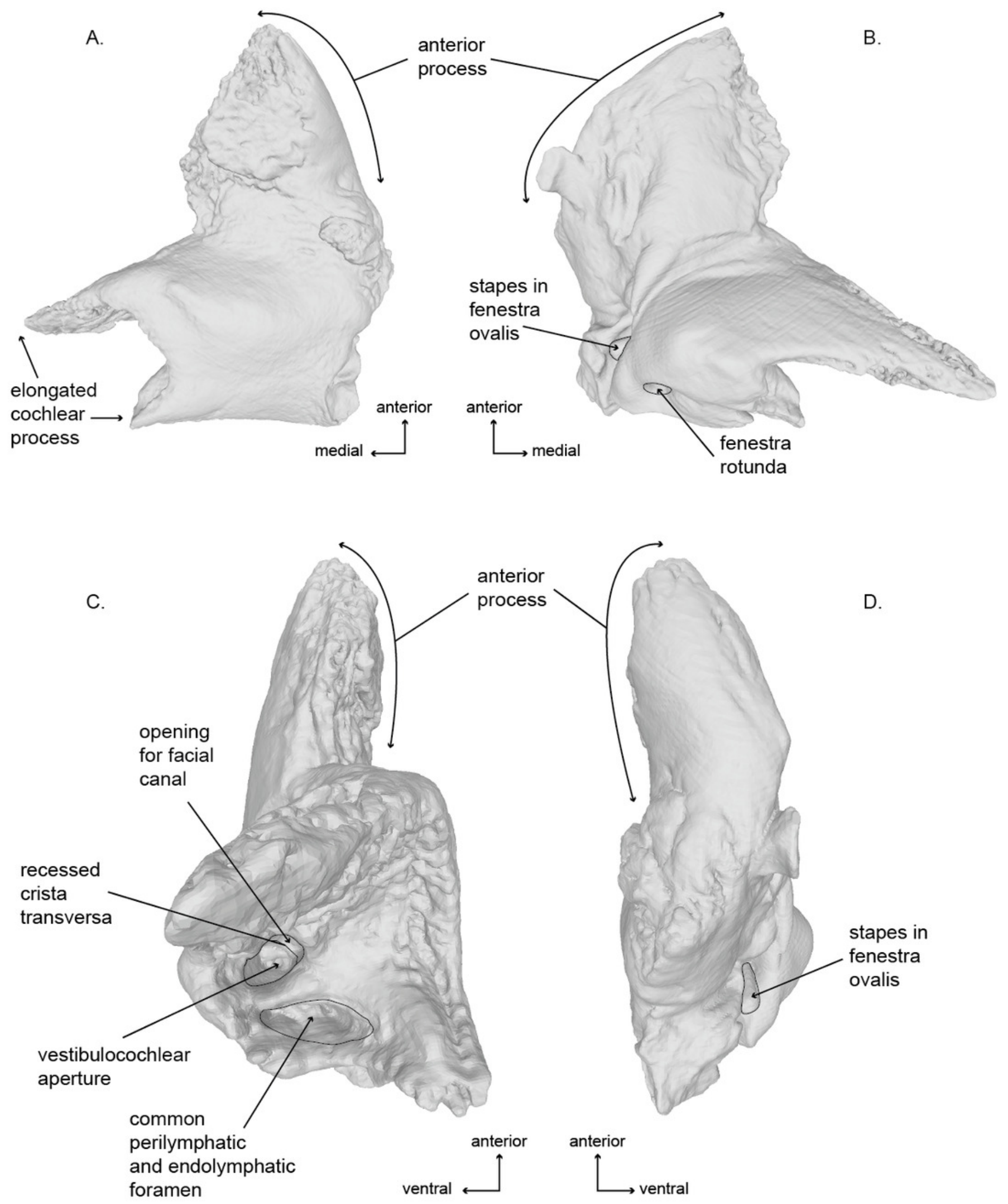


\section{Figure 7}

Comparisons of the vertex and dorsal surface of the cranium of Norrisamina miocaena with some extant baleen whale species based on available 3D models.

A. Caperea marginata Gray 1846 (NHMUK 1876.2.16.1), B. Eubalaena australis (NHMUK 1873.3.3.1), C. Balaenoptera edeni Anderson 1878 (NHMUK 1920.12.31.1), D. Megaptera novaeangliae Borowski 1781 (NHMUK 792a), E. Norrisanima miocaena (USNM 10300), F. B. physalus (NHMUK 1862.7.18.1), G. B. acutorostrata (NHMUK 1965.11.2.1), H. B. borealis (NHMUK 1934.5.25.1), I. B. musculus (NHMUK 1892.3.1.1). All NHMUK scans were downloaded from https://doi.org/10.5519/0020467, with the exception of the blue whale which was acquired from https://sketchfab.com/NHM Imaging (Sabin et al 2018), and humpback whale, which was made available directly from the NHMH to the authors. 
A. Caperea marginata

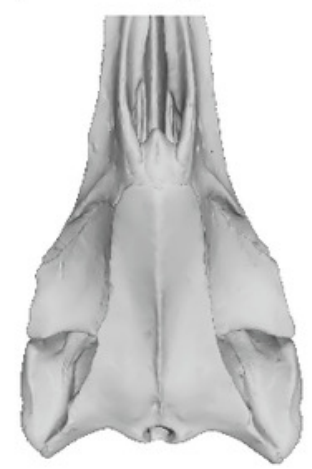

D. Megaptera novaeangliae

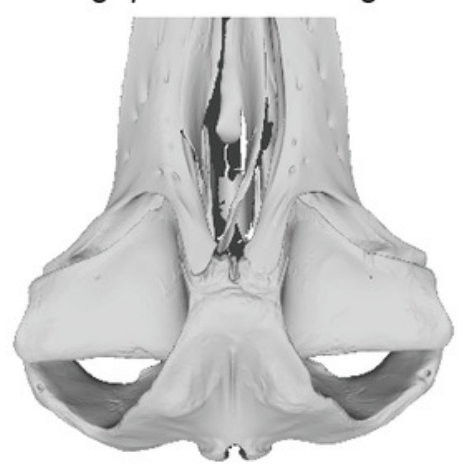

G. Balaenoptera acutorostrata

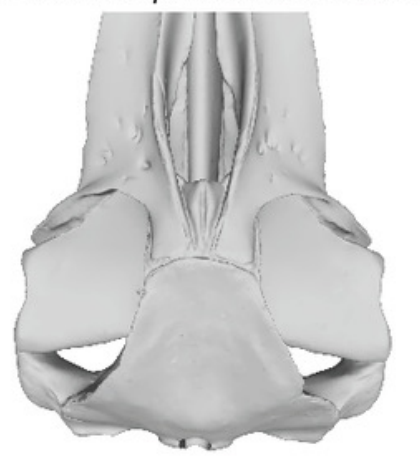

B. Eubalaena australis

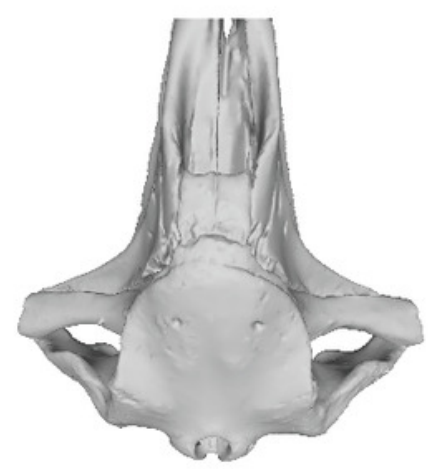

E. Norrisanima miocaena

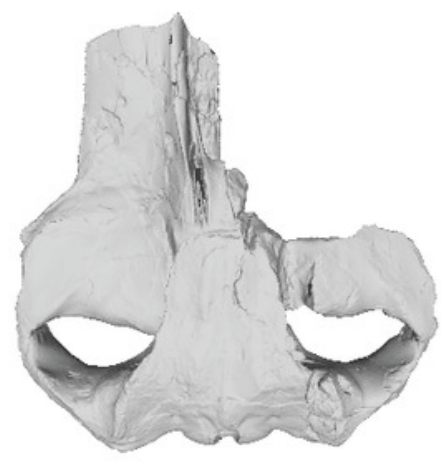

H. Balaenoptera borealis

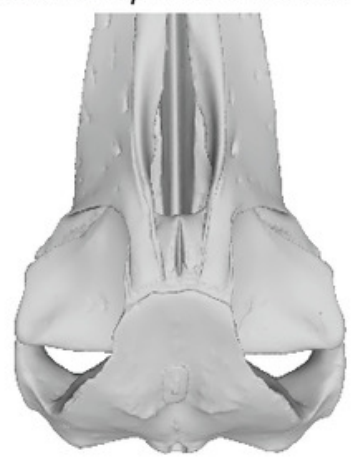

C. Balaenoptera edeni

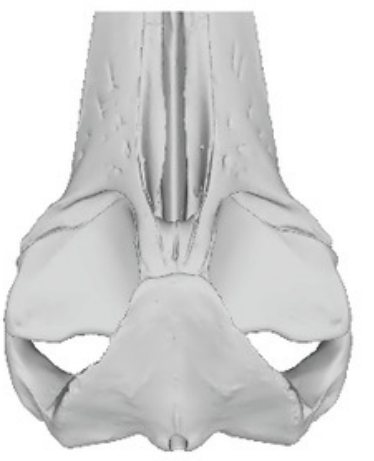

F. Balaenoptera physalus

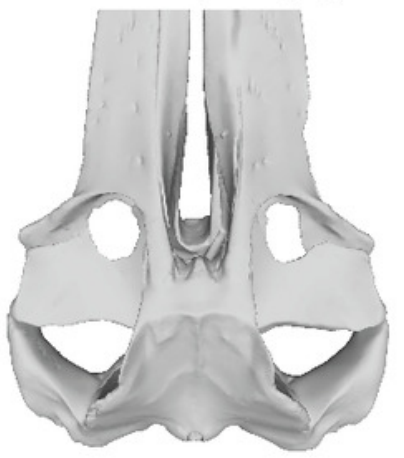

I. Balaenoptera musculus

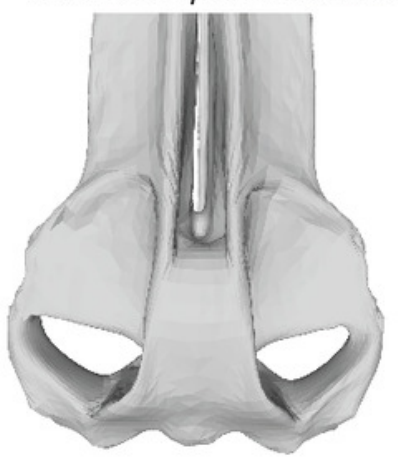




\section{Figure 8}

Comparisons of the right periotic of Norrisamina miocaena with extant species within Balaenoptera and Megaptera (except for $\mathrm{C}$, all specimens are the right periotic; all are shown in ventral view with the anterior oriented up).

Balaenoptera bonaerensis (USNM504953), B. B. borealis (USNM504699) C. B. physalus (USNM 237566), D. Norrisanima miocaena (USNM 10300), E. Megaptera novaeangliae (USNM 486175). N. miocaena is enlarged with a scale bar at $1 \mathrm{~cm}$; the scale bar for other periotics is $10 \mathrm{~cm}$. Numbered characters are listed in Table 1: 1) Aperture of cranial nerve (CN) ducts deeply recessed in pars cochlearis (PC), 2) Aperture of $\mathrm{CN}$ ducts erupt medial; not deflected dorsally, 3) Dorsoventrally flat and mediolaterally elongate PC, 4) Short and robust anterior process (AP) relative to size of $P C, 5$ ) Presence of lateral crest on the ventral surface of $A P, 6$ ) Sharply pointed triangular flange, 7) Posteriorly deflected triangular flange, 8) Concave medial margin of PC, 9) Transverse ridge on ventral surface of PC, 10) Deep invagination of fenestra ovalis. 


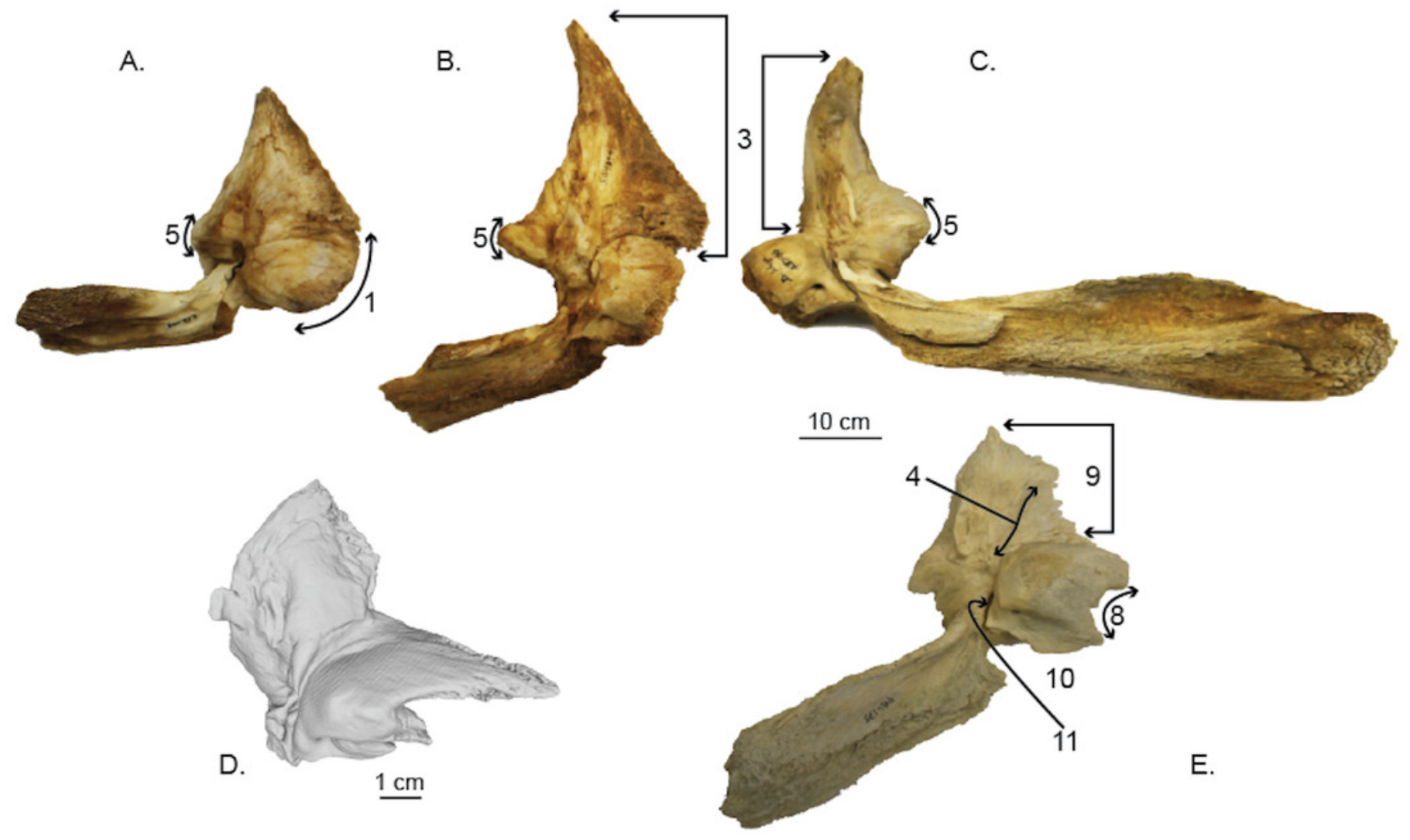

